\title{
Timing as a Mechanism of Development and Evolution in the Cerebral Cortex
}

\author{
Laura R. Fenlon ${ }^{a, b}$ \\ ${ }^{\text {aS }}$ chool of Biomedical Sciences, Faculty of Medicine, The University of Queensland, Brisbane, QLD, Australia; \\ ${ }^{\mathrm{b}}$ Queensland Brain Institute, The University of Queensland, Brisbane, QLD, Australia
}

\section{Keywords}

Brain development - Brain evolution - Cerebral cortex ·

Evolution of nervous systems · Heterochrony

\begin{abstract}
One of the biggest mysteries in neurobiology concerns the mechanisms responsible for the diversification of the brain over different time scales, i.e. during development and evolution. Subtle differences in the timing of biological processes during development, e.g. onset, offset, duration, speed and sequence, can trigger large changes in phenotypic outcomes. At the level of a single organism, altered timing of developmental events can lead to individual variability, as well as malformation and disease. At the level of phylogeny, there are known interspecies differences in the timing of developmental events, and this is thought to be an important factor that drives phenotypic variation across evolution, known as heterochrony. A particularly striking example of phenotypic variation is the evolution of human cognitive abilities, which has largely been attributed to the development of the mammalian-specific neocortex and its subsequent expansion in higher primates. Here, I review how the timing of different aspects of cortical development specifies developmental outcomes within species, including processes of cell proliferation and differentiation, neuronal migration and lamination, and axonal targeting and circuit maturation. Some examples of the ways that different processes
\end{abstract}

Karger@karger.com www.karger.com/bbe

Karger!"
(C) 2021 The Author(s)

Published by S. Karger AG, Basel

This is an Open Access article licensed under the Creative Common Attribution-NonCommercial-4.0 International License (CC BY-NC) (http://www.karger.com/Services/OpenAccessLicense), applicable to the online version of the article only. Usage and distribution for commercial purposes requires written permission. might "keep time" in the cortex are explored, reviewing potential cell-intrinsic and -extrinsic mechanisms. Further, by combining this knowledge with known differences in timing across species, timing changes that may have occurred during evolution are identified, which perhaps drove the phylogenetic diversification of neocortical structure and function.

(c) 2021 The Author(s).

Published by S. Karger AG, Basel

\section{Introduction}

\section{Timing in Development and Evolution}

Across the life span of an organism, time plays a role in all events, from nanosecond-scale molecular changes within single cells, to circadian rhythms of the whole organism, to aging processes over decades. The different timing of developmental processes in the field of evolutionary biology is described by the term "heterochrony", defined by Haeckel, where changes in the onset, offset, duration, speed or sequence of developmental events can substantially change the phenotype of an organism (Fig. 1) [De Beer, 1940; Gould, 1977]. Indeed, De Beer [1940] considered heterochrony a powerful evolutionary force, such that small changes in timing could enable so rapid an evolutionary change that gaps in the fossil record would be expected. The examination of developmental events relative to one another, and between species, relies 


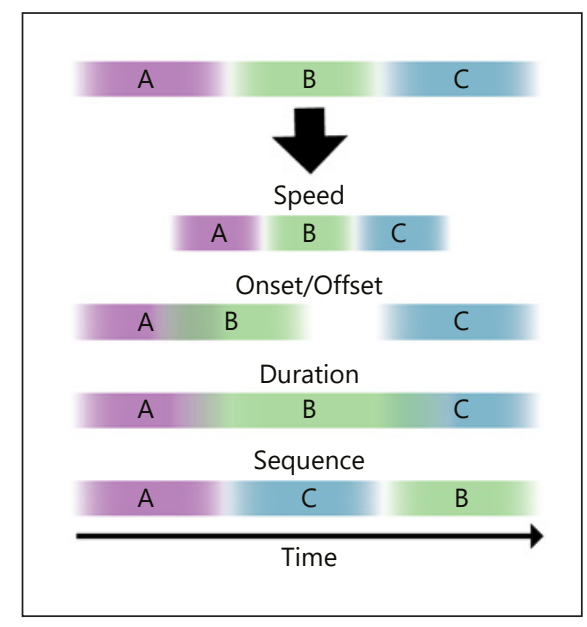

Fig. 1. Schematic of different possible heterochronies in a series of developmental modules (A, B and C), outlining example shifts of overall speed for all modules, and relative change in onset/offset and duration for $\mathrm{B}$, and a swapped sequence for $\mathrm{C}$ and $\mathrm{B}$.

on an assumption of modularity, as, although overall development is unidirectional, some of its less interdependent modules can be temporally varied within an ontogenic series. Such discrete processes are themselves temporal, in that they have an onset and a termination, as well as directional, in that they proceed irreversibly in only one direction over time. Of course, some developmental modules are inherently interdependent, and mostly occur within a "set series," and the question of which modules might be more amenable to temporal variance has long fascinated evolutionary biologists, given their potential to vary across ontogeny and phylogeny. Heterochronic divergence can result in phenomena such as paedamorphosis, due to neotony (the retention of juvenile traits into the adult form) or progenesis (the acceleration of developmental processes), as well as peramorphosis (delayed maturation with extended periods of growth). Indeed, a common overarching explanation of human evolution is that it represents an extended neoteny, where there is a significant prolongation of childhood and retardation of maturity, as well as the retainment of originally juvenile features of hominid ancestors [Gould, 1977].

The rapid rise in genome sequencing and genetic knockouts in the 1990s shifted the focus of most biological fields to genes, including differences in sequences between species, and the function of particular genes in living organisms (or rather, what functions are lost in the absence of a gene). Recently, a renewed interest in less gene-centric mechanisms of development and evolution has emerged, including the role of epigenetics, driven partly by the realisation that very different phenotypes can result from a similar genome. In no organ is this phenomenon so striking as in the brain, as exemplified by the remarkable difference in form and function of human and chimpanzee brains, despite $99 \%$ similarity of the protein-coding sequences in their genomes [Wildman et al., 2003]. The neocortex in particular is unique to mammals and shows incredible diversity in development and architecture between species, coordinating a wide range of sensory, cognitive and motor functions.

Many hundreds of genes have been identified that affect the formation of the cerebral cortex. However, due in part to the "all or nothing" nature of traditional single gene knockouts, the role of timing in gene expression and developmental processes has been more difficult to study using these traditional tools and therefore has attracted less attention. The differential timing of processes may be a uniting factor in the role of diverse gene pathways and families, and timing may also be affected by and cause phenotypes independently from genetic variation. This review will focus on the concept of time crucially underlying cortical development and evolution, with the aims of broadly synthesising the current evidence relating changes in timing to adult outcome within each major subprocess of cortical development (section 2), speculating on various timekeeping mechanisms that may be amenable to developmental and evolutionary change (section 3) and reviewing known phylogenetic divergences in developmental timing and potential mechanistic drivers of these throughout cortical evolution (section 4).

\section{Overview of Cortical Development}

The neural tube is initially made up of neuroepithelial cells, which divide symmetrically to generate a large multipotent founder pool that is able to produce neurons, astrocytes and oligodendrocytes [Davis and Temple, 1994; Florio and Huttner, 2014]. At around embryonic day (E)11 in the mouse, neuroepithelial cells become apical radial glial cells, which have bipolar morphologies with apical and basal attachments to the ventricular and pial surfaces [Noctor et al., 2001]. Apical radial glial cells can be distinguished from neuroepithelial cells based on their differential expression of markers and division strategies [Götz and Huttner, 2005]. This transition is generally considered to mark the beginning of neurogenesis in the cortex, as apical radial glial cells are able to undergo symmetric divisions to expand their population, like neuroepithelial cells. However, apical radial glial cells also commonly divide via asymmetric division to renew them- 


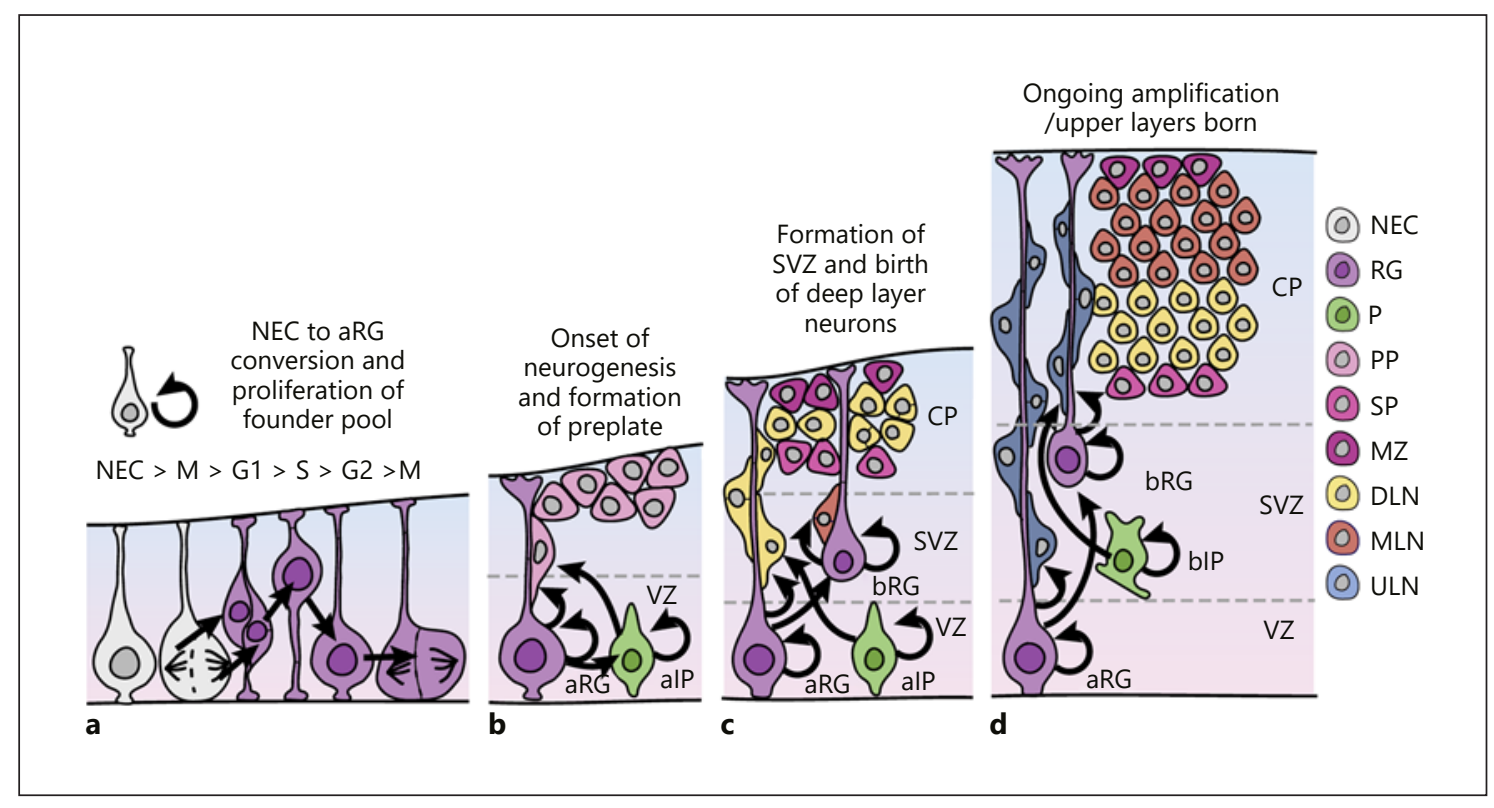

Fig. 2. Schematic overview of major steps of early rodent cortical development. a Neuroepithelial cells (NECs) convert to apical radial glia (aRG) which both undergo symmetric division to expand the founder pool. b At the onset of neurogenesis, radial glia divide asymmetrically to self-renew and to produce apical or basal intermediate progenitor cells (IP) or preplate neurons. c The preplate splits into the subplate (SP) and marginal zone (MZ), and newborn deep layer neurons (DLN) migrate between these layers to begin expansion of the cortical plate. $\mathbf{d}$ Middle layer neurons (MLN) and upper layer neurons (ULN) are born successively, increasingly from intermediate progenitor cells, and continue to populate the cortical plate.

selves, and produce a neuron via direct neurogenesis, or an intermediate progenitor that subsequently produces a neuron via indirect neurogenesis [Noctor et al., 2004]. Another type of radial glia, basal radial glia, are situated in the subventricular zone, where they maintain a basal process with the pial surface but lack contact with the ventricular surface. Like apical radial glia, basal radial glia can divide to self-renew and/or produce neurons and intermediate progenitors. They rarely occur in lissencephalic (smooth cortex) species such as the mouse, but are common in gyrencephalic (folded cortex) species, in which they form the outer subventricular zone, and are thought to contribute to the evolutionary expansion of superficial cortical layers [Fietz et al., 2010; Hansen et al., 2010; Gertz et al., 2014; Vaid et al., 2018].

Most intermediate progenitor cells are multipolar, the best-known example being basal intermediate progenitors, express Tbr2 [Englund et al., 2005], and delaminate from the ventricular zone to reside in the subventricular zone, where they can divide symmetrically to self-renew, or to generate neurons [Haubensak et al., 2004; Noctor et al., 2004]. Apical intermediate progenitors (also known as short neural precursors) comprise another population of intermediate progenitors, which maintain an apical process contacting the ventricle and a basal process that is detached from the pial surface. These cells remain in an apical location where they predominantly generate neurons [Gal et al., 2006]. Very early neurogenesis is thought to mostly consist of neurons born from radial glia, while late neurogenesis involves more contributions from intermediate progenitor cells. Neurons arising from each of these progenitor subtypes are born sequentially from deeper-to-upper layers [Angevine and Sidman, 1961; Molyneaux et al., 2007], using the basal processes of the radial glia along which they migrate to populate the cortex.

The first phase of neurogenesis produces preplate cells such as Cajal-Retzius cells, which join other preplate cell types migrating from extracortical origins [Gorski et al., 2002; Bielle et al., 2005]. The next wave of newborn neurons then splits this preplate into the marginal zone (layer 1) and subplate, proceeding to generate the other cortical layers in an inside-out manner [Olson, 2014] (Fig. 2). During migration, pyramidal neurons express a complement of transcription factors that start to define their molecular and projection identity, initially growing direc-
Fenlon 


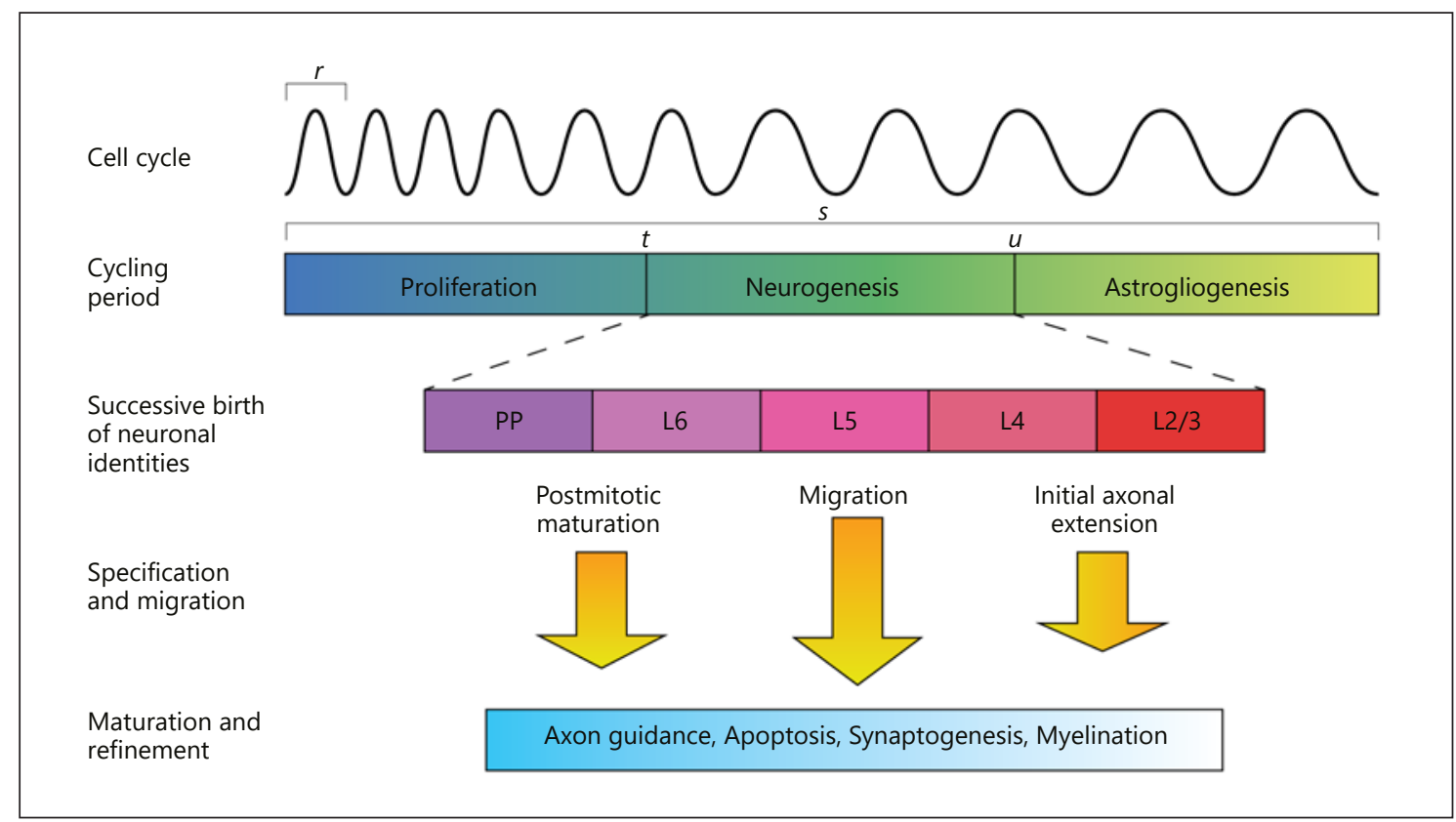

Fig. 3. Schematic of modules comprising neocortical development. The length of the cell cycle gradually increases across development, during which progenitor cells switch from proliferative to neurogenic divisions, and then again to astrogliogenic divisions. During neurogenesis, there is a successive generation of neuronal identities from deep to upper layer neurons. Following birth, each neuron completes a period of postmitotic maturation, which involves the expression of transcription factors, migration to the appropriate cortical layer and extending an initial axon. Finally, there is a period of maturation and refinement that extends into postnatal life, involving temporally overlapping processes of axon guidance, apoptosis, synaptogenesis and myelination.

tional axons that extend towards their appropriate target, followed by dendrites once the neuron is situated in its appropriate layer. The end of neurogenesis occurs when the radial glia undergo terminal divisions that produce astrocytes and oligodendrocytes instead of neurons, a process that takes place from E16-17 in mice [Gao et al., 2014]. A period of remodelling, synaptic pruning/stabilisation, cell death and glial/myelin maturation follows, in which external cues help to fine-tune brain organisation and function into the ultimate adult form [Jiang and Nardelli, 2016].

In addition to the glutamatergic neurons and glia born from the cortical ventricular zones, a number of other cell types arising from extracortical origins contribute to the final composition of the cortex [Silva et al., 2019]. At the onset of corticogenesis, subplate neurons, Cajal-Retzius cells and other glutamatergic cell types migrate tangentially from outside the neocortex and form the preplate [Bielle et al., 2005; Barber and Pierani, 2016]. Next, cortical interneurons are born in the subpallium and migrate in tangential streams along the cortical wall to populate the cortical plate [Faux et al., 2012]. Blood vessels also progressively invade the cortical plate, with microglia predominantly entering via these blood vessels [Ginhoux and Prinz, 2015]. At later stages of cortical development, oligodendrocyte precursor cells, which are born in the ventral forebrain, also migrate tangentially to populate the developing cortex [Choe et al., 2014]. Finally, corridor cells migrate from the subpallium, and channel ingrowing thalamocortical axons, which have a waiting period in the subplate prior to entering the cortical plate [Kostović and Judas, 2010; Hoerder-Suabedissen and Molnár, 2015]. Each of these steps of cortical development can be framed as different modular sequences, all of which have their own speed, onset, offset and duration.

\section{Timing in Cortical Ontogeny}

In this section, the evidence for how changes in timing of different modules of neocortical development impact developmental outcome will be reviewed. These modules are interdependent to varying degrees, as well as variably dependent on their preceding steps, and it can therefore 
be simpler to draw concrete conclusions from manipulations of earlier processes, such as cell cycle, than later ones. In this section I will concentrate on the consequences of changing developmental time on outcome (i.e., what is time instructing?), and address the mechanisms by which time is counted by tissues (i.e., what is instructing time?) in more detail in section 3.

\section{The Length of a Single Cell Cycle}

The length of a single cell cycle (Fig. 3, r) is variable between cell types and tissues, as well as across a life span. Early work used birthdate labelling to correlate cell cycle lengths with the proportion of neurons across different cortical areas, with modelling data demonstrating that simply accelerating the speed of the cell cycle, without changing other parameters, would have a linear impact on the number of neurons produced (i.e., doubling the length of a cell cycle produces half as many neurons) [Polleux et al., 1997]. In the cortex, the total cell cycle of neural progenitor cells lengthens as development progresses [Takahashi et al., 1995; Calegari et al., 2005]. Specifically, mitosis [Haydar et al., 2003] and G1 phase [Takahashi et al., 1995; Lukaszewicz et al., 2005] lengthen over the course of development, which is linked to the increasing likelihood of asymmetric divisions and neurogenesis, whereas a shorter $S$ phase is linked to differentiation [Arai et al., 2011]. Indeed, markers known to be expressed by progenitors about to produce neurons (Btg2 aka Tis21[Iacopetti et al., 1999] and Cend 1 aka Bm88 [Georgopoulou et al., 2006]) have been experimentally demonstrated to inhibit G1 progression. Other general factors that promote differentiation increase G1 length, while factors that promote mitosis decrease G1 length [Lukaszewicz et al., 2002].

In addition to being affected by differentiative cues, there is clear evidence that cell cycle length also instructs the proliferative versus differentiative outcome of progenitor divisions. A pioneering study by Calegari and Huttner [2003] causally linked G1 lengthening to different outcomes of neurogenesis by inhibiting cyclin-dependent kinases and therefore lengthening G1 progression ectopically. The authors found premature upregulation of neurogenic markers, as well as the premature generation of neurons [Calegari and Huttner, 2003]. This finding was later expanded upon by others who showed that lengthening cell cycle duration with other experimental methods increases neurogenesis at the expense of progenitor production [Lange et al., 2009; Pilaz et al., 2016; Mitchell-Dick et al., 2019]. In contrast, by either overexpressing Cdk4 and Ccnd1 [Lange et al., 2009] or Ccnd1 and Ccne1 [Pilaz et al., 2009], researchers have been able to shorten G1 in the cerebral cortex, producing a delay in and reduction of neurogenesis with a concomitant increase in proliferative divisions and an expansion of the pool of basal progenitors.

\section{Length of Total Cycling Period and Proliferative, Neurogenic and Astrogliogenic Windows \\ Length of Total Cycling Period}

If the rate at which progenitor cells are cycling affects the final number of cortical cells, it follows that the length of time in which they are able to cycle (Fig. $3, s$ ) will also influence the number of total cycles and therefore the final cell number. It has been reported that, independently of location, mouse neocortical neural progenitors undergo approximately 11 cycles over a 6-day window [Takahashi et al., 1999]. This number is thought to be plastic, with manipulations such as ectopic microinjection of Fgf2 reported to increase the number of rounds of divisions without affecting cell cycle length, thereby increasing the volume and total number of neurons in the adult cortex [Vaccarino et al., 1999]. Within this time, cells also transition between proliferative (primary symmetric) divisions (until E11-12 in the mouse [Gao et al., 2014]), to neurogenic (asymmetric) divisions (until E17-18 in the mouse), and finally to gliogenic divisions, after which they stop dividing. Two successive waves of demethylation in apical progenitors coincide with these periods and are thought to regulate the response of these cells to extracellular cues that are present throughout development [He et al., 2005; Sanosaka et al., 2017]. The relative timing of each of these switches is also important for controlling the final neuronal number and identity.

Timing of the Switch between Proliferative and Neurogenic Divisions

A number of studies have been able to ectopically delay the timing of the switch between proliferative and neurogenic divisions (Fig. 3, t), for instance by knockout of Foxc1, which reduces retinoic acid production from the meninges [Siegenthaler et al., 2009], P27 knockout [Caviness et al., 2003], sustained Foxp1 expression [Pearson et al., 2020], knockout of Fgf10 [Sahara and O'Leary, 2009], activation of $B$-catenin, a member of the Wnt pathway [Chenn and Walsh, 2002], perturbation of angiogenesis and oxygen delivery via Gpr124 knockdown [Lange et al., 2016], overexpression of Cdk4/Ccnd1 or Ccnd1/Ccne1 [Lange et al., 2009; Pilaz et al., 2009] to prevent cell cycle lengthening, and knockout of Gdpd5 (aka Gde2), which influences Notch signalling [Rodriguez et al., 2012]. With 


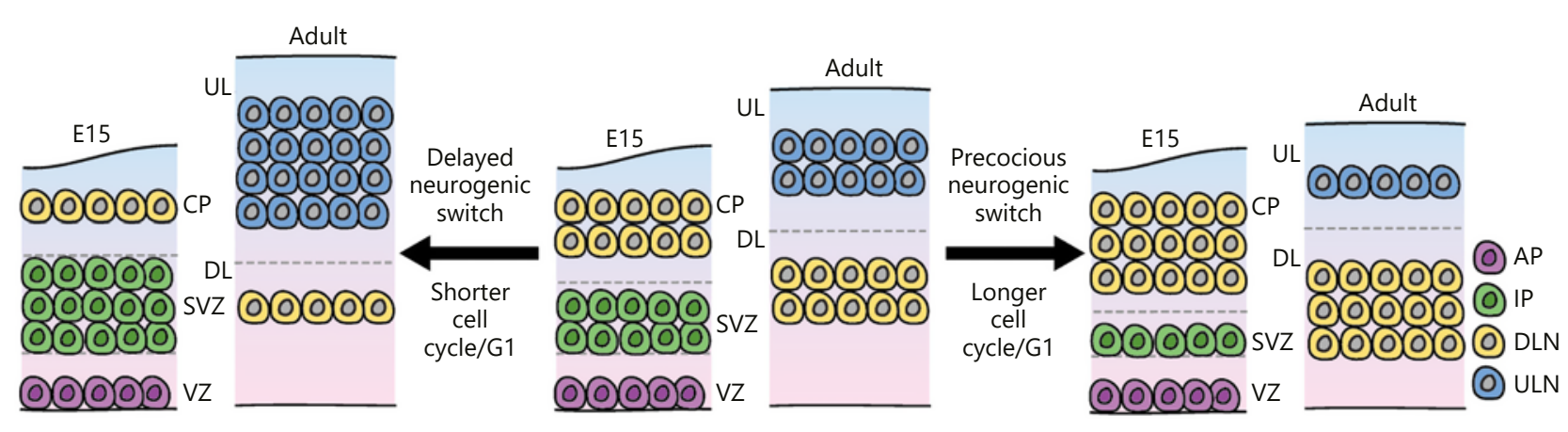

Fig. 4. Schematic of generalised effects of experimentally inducing a delayed (left) or precocious (right) neurogenic switch in the embryo and adult. In the case of a delayed neurogenic switch, apical progenitors (AP) initially produce more intermediate progenitor (IP) cells at the expense of neurons, and this leads to an expansion of upper layer neurons (ULN) at the expense of deep layer neurons
(DLN) in the adult and a larger overall cortex. When neurogenesis is induced precociously, more neurons are initially produced at the expense of progenitor expansion, which results in more deep layer neurons, while upper layer neurogenesis is limited by the reduced founder pool and the cortex is smaller overall. some variations, perhaps due to additional roles of these proteins in development and/or to differences in the method and time of investigation, these studies reveal pieces of a general pattern whereby delaying the onset of neurogenesis leads to an expanded pool of progenitor cells (radial glia and/or intermediate progenitors), initial$l y$ at the expense of new neurons. This is followed by a late en masse differentiation of neurons from a larger pool of progenitors, resulting in more neurons, larger cortices and a tendency to produce more upper layer neurons at the expense of deep layer neurons postnatally. The only one of these studies to have investigated astrocyte number [Rodriguez et al., 2012] found no difference in the Gdpd5 knockout cortex relative to wild type at postnatal day $(\mathrm{P}) 0$, suggesting that delaying the onset of neurogenesis may not necessarily affect the astrogliogenic period that follows.

In contrast to delaying the switch from proliferative to neurogenic divisions, inducing precocious neurogenic divisions/differentiation has been achieved via knockdown of Hif1a [Lange et al., 2016], ectopically sustained Ikzf1 [Alsiö et al., 2013], P27 overexpression [Caviness et al., 2003], reduced expression of Smad1/5, which are involved in Bmp signalling [Najas et al., 2020], inactivation effectors of Notch signalling [Hatakeyama et al., 2004] or lengthening of $\mathrm{G} 1 /$ mitosis via Cdk4/Ccnd1 inhibition [Lange et al., 2009], Magoh depletion [Pilaz et al., 2016] or pharmacological agents [Mitchell-Dick et al., 2019]. These studies have generally shown decreased progenitor expansion, often initially in association with increased

Keeping Time in Cortical Development and Evolution neuronal production. However, ultimately the mature brain is often smaller with fewer neurons because of the reduced founder pool, as well as potentially increased rates of apoptosis. These studies also differ in terms of the outcome of these manipulations on lamination, with either indiscernible changes in the ratio of layers, or a relative increase in deep layer neurons at the expense of upper layer neurons or astrocytes, depending on the mechanism of manipulation [Hatakeyama et al., 2004; Alsiö et al., 2013; Najas et al., 2020]. Broadly speaking, these findings from delayed or precocious neurogenesis are generally in line with predictions of laminar fate from a model of altering the balance of cells that exit the cell cycle (Q) versus those that re-enter the cell cycle $(\mathrm{P})$, where a higher proportion of $\mathrm{Q}$ is caused by or concomitant with a longer G1 and leads to precocious neurogenesis, a smaller adult cortex with more deep layer neurons at the expense of upper layer neurons, while a higher $\mathrm{P}$ shows the exact opposite effects (Fig. 4) [Caviness et al., 2003].

Timing of the Switch between Neurogenic and Gliogenic Divisions

Various studies have ectopically extended the period of neurogenesis (i.e., delayed the switch to gliogenesis; Fig. $3, u$ ) in a number of ways, including via cross-gestation between strains with physiologically different gestational periods [Stepien et al., 2020], depletion of the mRNA modifier $\mathrm{m}^{6} \mathrm{~A}$ [Yoon et al., 2017], perturbation of the gp130-Jak-STAT pathway [Barnabé-Heider et al., 2005] and inactivation of members of the epigenetic 
modifier Polycomb group that normally suppress neurogenic factors such as Neurog1 [Hirabayashi et al., 2009]. While many of these studies have shown that fewer astrocytes are present during or shortly after extended neurogenesis in manipulated cortices, it remains unclear whether or not they are able to "catch up" at later periods. In contrast, precocious termination of neurogenesis via knockdown of known neurogenic factors such as Neurog2 and Ascl1 aka Mash1 [Nieto et al., 2001], Erbb4 knockout [Sardi et al., 2006] or activation of the gp130Jak-STAT pathways [Barnabé-Heider et al., 2005] causes early and excessive astrogliogenesis at the expense of cortical neurons.

\section{The Timing and Sequence of Successive Birth of}

Different Identities of Neurons

The average of 11 cell cycles over a 6-day window described for mouse progenitors has previously been correlated with progeny identity. The main reasoning behind this is that the same cycle number (e.g., cycle 5 of 11) will usually give rise to cells of similar identity, even if that cycle occurs on different days for different progenitors (e.g., in extreme rostral vs. caudal parts of the brain) [Takahashi et al., 1999]. A mechanism that is partially cell-intrinsic but refined by cell-extrinsic cues is thought to be involved in this sequence, as clonal culture of progenitors has been shown to produce comparable sequences of progeny fate [Qian et al., 2000; Shen et al., 2006]. However, this progression is more limited in isolated progenitors, where cell-cell contacts are prevented [Okamoto et al., 2016]. Early work suggested that progenitors harvested early enough in cell cycle (S phase) and transplanted into older brains adopted the appropriate laminar fate for the new (older) environment, whereas progenitors transplanted into a younger brain were unable to adapt and retained their original lamination destination [Desai and McConnell, 2000]. However, this finding has recently been updated by a study that showed that apical progenitors can in fact enter younger states following heterochronic transplantation into younger brains, whereas intermediate progenitor cells remain committed [Oberst et al., 2019]. Therefore, the inherent differentiation potency of apical progenitor cells is not progressively and irreversibly restricted during the course of neurogenesis.

Although apical progenitors can be experimentally manipulated to produce a range of cell fates, debate remains over whether or not all apical progenitor cells do in fact generate all types of cortical neurons, with some work suggesting that subpopulations exist that only contribute to certain cortical layers [Franco et al., 2012; Gar-
cía-Moreno and Molnár, 2015; Ellender et al., 2019]. In contrast, other studies have concluded that all radial glia produce neuronal fates distributed across all cortical layers, with each radial glial cell producing outputs of a similar size (8-9 neurons) and composition [Guo et al., 2013; Gao et al., 2014]. A recent investigation combined numerous lineage-tracing methods, the disparate usage of which may have contributed to the varying results across previous studies, and found that the majority of radial glia generate multiple neuronal fates, while a small fraction produce progeny that are fate-restricted to specific cortical layers [Llorca et al., 2019]. Progenitors that may be fate-restricted to produce upper layer neurons have been termed "delayed progenitors." However, although recent evidence shows that the temporary experimental arrest of the cell cycle in progenitors can cause them to skip production of deep layer neurons and only produce upper layer neurons [Okamoto et al., 2016], more research is needed to understand whether and how progenitors are delayed in vivo.

A recent study used flash-tag and single-cell RNAseq to label and sequence apical progenitors at the same differentiation state over different embryonic days (age axis), as well as throughout different differentiation states as single progenitors aged (differentiation axis). The authors concluded that neuronal identity is conferred via the action of generic differentiation programs on age-dependent identities over the course of development [Telley et al., 2019]. What, then, regulates these age-dependent identities of apical progenitor cells? Identifying factors that change over time has been a popular method of finding candidates to answer this question, although the interpretation of the subsequent findings is complicated by the fact that a single age point can produce various neuronal fates [Magrinelli et al., 2018; Llorca et al., 2019]. In addition to progressive hyperpolarisation of apical progenitors (discussed in detail in section 3.4), only a handful of transcriptional regulators have been found that are expressed differentially over time by apical progenitors and that direct the timing and sequence of neuronal identity specification. Foxg1 is expressed when cells switch from producing Cajal-Retzius cells to deep layer neurons. Experiments that induce the loss of Foxg1 after this switch result in the ectopic generation of Cajal-Retzius cells at later time points than that at which they would usually be generated [Hanashima et al., 2004]. Loss of Prdm16. which regulates genes that are dynamically expressed between early and late neurogenesis, results in the extended production of deep layer neurons into periods when progenitors would usually be producing more superficial 
neurons [He et al., 2021]. A recent article reported that opposing gradients of microRNAs (miR-9, miR-128 and Let-7) are expressed in progenitors throughout development, and that transient alterations of their expression can shift neuron production from early-to-later born fates and vice versa [Shu et al., 2019]. The manipulation of cues that are secreted by other cellular populations and act on apical progenitors non-cell autonomously has also been shown to shift the timing of this transition and will be discussed in more detail in sections 2.7 and 3.3.

\section{Timing of Postmitotic Maturation}

The difficulty of identifying molecularly distinct progenitor populations that give rise to different subtypes of neurons indicates that many of the factors involved in the specification of neuronal identity subtypes may occur postmitotically. Indeed, many of the transcription factors known to specify neuronal identities (e.g., Satb2 and Bcl11b aka Ctip2) are only expressed once progenitor cells have terminally divided [Srinivasan et al., 2012; Paolino et al., 2018]. Transcription factors that specify many types of neurons are initially expressed together in the same postmitotic cell as part of a relatively conserved differentiation programme [Telley et al., 2019], with this network being refined by as yet unclear mechanisms that likely involve translational priming and repression [Azim et al., 2009; Zahr et al., 2018]. Experimental manipulations that alter the timing and sequence of neuron identity specification have therefore largely comprised manipulations of the transcription factors that specify neuronal fate postmitotically. These experiments have shown that overexpression of the callosal neuron specifier Satb2 at a precocious stage [Britanova et al., 2008; Paolino et al., 2020] can respecify would-be deep layer subcerebrally projecting neurons to a more upper layer neuron identity, including the associated molecular and connectivity features. In contrast, ectopic overexpression of the deep layer specifier Fezf2 [Molyneaux et al., 2005; Chen et al., 2008] or Bcl11b [Chen et al., 2008; Paolino et al., 2020], or knockdown of Satb2 [Shinmyo and Kawasaki, 2017; Paolino et al., 2020] at a late stage when upper layer neurons are born is sufficient to respecify upper layer neurons towards a more deep layer neuron pattern of gene expression and connectivity. This shows that changes in the timing and sequence of neuronal identity differentiation and maturation can change the composition, and therefore the connectivity and likely ultimate functionality, of the cortex.

\section{Timing of Migration}

While much is known about the causal role of timing in neurogenic events, the role of migration timing is far less clear. Part of the reason for this may be that it is experimentally difficult to separate changes in migration from prior alterations, e.g. in cell cycle, when studying knockout models, as well as the overlapping function of many genes. There are three main modes of migration: somal translocation, multipolar migration and locomotion. Migration strategies differ throughout development [Chew et al., 2014] and evolution [García-Moreno and Molnár, 2020] but a general model involves newborn neurons first undergoing multipolar migration through the regions below the cortical plate. At this stage, a pause or "sojourn" lasting around $24 \mathrm{~h}$ in the mouse has been reported for multipolar cells within the subventricular zone, during which time they extend and retract processes and move in non-specific directions [Tabata and $\mathrm{Na}$ kajima, 2003; Noctor et al., 2004; Jossin and Cooper, 2011]. Proposed functions of this pause have included receiving/processing cues that influence subsequent polarisation direction, as well as coordination with the influx of GABAergic interneurons into the cortex [Noctor et al., 2004; Hansen et al., 2017]. Whether the length of this pause changes across development, cell type or species, and therefore whether its duration has functional importance to cortical development, is an intriguing topic for future study. Subsequent interaction with the subplate, including transient NMDA receptor-mediated synapses, elicits a change from multipolar to bipolar morphology and thereby to a locomotion migration mode along radial glial scaffolds [Ohtaka-Maruyama et al., 2018], as well as likely contributing to the specification of cortical projection neurons [Ozair et al., 2018]. Somal translocation, which generally occurs in the final stages of migration, has been reported to have a faster overall speed than the locomotion mode, which in turn is faster than multipolar migration [Nadarajah et al., 2001; Tabata and Nakajima, 2003]. Therefore, changes in the proportion of a given progenitor population's migration strategy may affect the overall speed of migration for that population. In vitro modelling has shown that the major determinants of the average migration speed for a given neuron are saltatory event frequency and duration, rather than nucleokinetic speed itself [Nichols et al., 2008]. The duration of migration to some extent appears to be cell-intrinsic, as human cells transplanted into mouse cortex retain the longer human migration timings found endogenously in the human brain than mouse cells transplanted into mice [Marchetto et al., 2019]. 
Four major migration defects have been recognised: initiation defects, ongoing migration defects, lamination defects and stop signal defects [Bielas et al., 2004]. The genes implicated in migration defects, many of which may involve changes in timing among other actions, are too numerous to detail and have been summarised elsewhere [Cooper, 2014; Buchsbaum and Cappello, 2019]. However, a few key studies that have examined the effects of delayed or precocious migration on cortical development will be discussed here. Itoh et al. [2016] exploited the PDK1-Akt axis, which is known to regulate microtubule organisation, to slow down or speed up migration selectively in postmitotic neurons. Whereas the manipulation to slow down migration speed led to lamination defects, particularly affecting upper layer neurons, the manipulations speeding up migration were not examined at mature lamination stages, so the effects of this remain unclear [Itoh et al., 2016]. However, another study found that knockout of Flrt1/3, which are only expressed in a subset of migrating neurons, increased the rate of migration. A reduction in layer thickness was observed, especially in the lower layers, as well as the formation of ectopic sulci, which the authors suggested may be attributable to migration speed [Del Toro et al., 2017]. Foxg1 is usually downregulated by cells at the beginning of the multipolar phase of migration, and ectopic overexpression of Foxg1 during this stage delays migration through the intermediate zone and affects final laminar position, with more neurons positioned in the upper layers in the overexpression condition than the control [Miyoshi and Fishell, 2012]. In contrast to these varied defects, other studies have reported that various knockout mice with developmental migration delays can recover postnatally to exhibit normal adult lamination patterns [Wu et al., 2012; Martinez-Garay et al., 2016; Rashid et al., 2017]. Therefore, the role of migration speed and timing in cortical development remains unclear, with the varied results from previous experiments likely complicated by additional effects of genetic manipulations, as well as the mode of migration affected, the lag time between the precocial or delayed initiation, and the breadth of the neuronal population affected and hence the balance between the migration speed of a single neuron and its neighbours. Future studies using tools that enable precise spatiotemporal control of gene expression are required to selectively target different phases of migration and understand the roles that timing plays in each.

\section{Timing of Axon Extension, Growth and Guidance}

Timing of Initial Axon Extension

Axon extension is not a temporally separate process from migration, as initial axonal outgrowth generally occurs in the intermediate zone, when newly born neurons are beginning to enter the cortical plate [Hatanaka et al., 2015]. The two processes are therefore difficult to experimentally manipulate in isolation, and although there are myriad knockout models in which cortical axon guidance is affected, few if any have been demonstrated to affect timing specifically. However, the importance of timing in initial axon extension can be extrapolated by the strict regulation of timing during the normal course of development. For instance, early experiments by Richards et al. [1997] demonstrated that, initially, axons exiting the cortex project ventrolaterally towards the internal capsule (mouse E14, E15 and E16) and do not turn medially to pioneer the corpus callosum until E17 [Richards et al., 1997]. This work was further advanced by Hatanaka et al. [2015], who birth-dated neurons via electroporation, revealing that neurons labelled at E11.5 or E12 had almost exclusively lateral projections by E15.5, but that neurons labelled at E12.5 had a mixture of both medial and lateral projections. Further birth-dating via EdU injections at various time points following electroporation revealed that, amongst the neurons labelled via electroporation at E12.5, the earlier-born neurons (labelled with EdU) projected laterally, whereas the later-born neurons projected medially [Hatanaka et al., 2015]. Therefore, the order of cell birth appears to be intrinsically linked to cell fate and thereby the direction and timing of axon outgrowth, with the order of lateral-first and medial-second maintained even within a very tight time period (within E12.5). This strict timing sequence may in part be due to intrinsic factors that act to specify neuronal identity. For instance, the transcription factors Satb2 and Bcl11b are known to specify corticocortical and subcortical projection neurons, respectively. Both of these transcription factors are first expressed postmitotically in the intermediate zone, coinciding with the timing of initial directed axonal projection [Lickiss et al., 2012]; early laterally projecting neurons are predominantly Bcl11b positive whereas later medially projecting neurons are Satb2 positive [Hatanaka et al., 2015]. However, the early overexpression of Satb 2 in the mouse cortex, before Satb2 is usually expressed, has recently been reported to induce a lateral turning fate [Paolino et al., 2020], indicating that a combination of timing between both intrinsic factors and cellular environment likely controls the timing and direction of initial axonal outgrowth.
Brain Behav Evol 2022;97:8-32 DOI: $10.1159 / 000521678$
Fenlon 
Axon Growth and Guidance Timing

The final pattern of axonal connectivity in the neocortex depends on a sequence of precisely timed and complex cues that guide axons across the brain, sometimes spanning distances of centimetres. Numerous reviews have discussed the complex axon guidance mechanisms at play in different neocortical subtypes [Gobius and Richards, 2011; Kalil et al., 2011; Paolino et al., 2018; Stoeckli, 2018], but here we will focus on the major ways in which timing can impact connectivity outcome. The timing of axonal growth and guidance can be perturbed by the following three mechanisms (or a combination of them all): (1) timed changes in the axon guidance cues presented to growing axons and/or substrate availability over the course of development, (2) timed changes in axon guidance receptor expression or functionality over the course of development and (3) changes in the rate of axonal growth.

An example of the first mechanism has been demonstrated in the formation of the mouse corpus callosum, where researchers disrupted the timing of remodelling of the interhemispheric fissure via electroporation of Fgf8, thereby preventing growing callosal axons from crossing the midline, and therefore dramatically altering final brain connectivity [Gobius et al., 2016]. Interestingly, marsupials do not have a corpus callosum, and their midline is not remodelling during development [Gobius et al., 2017].

An example of the second mechanism is also necessary for proper formation of the corpus callosum, where axons are attracted to Sema3c via their Nrp1 receptors when approaching the midline. However, this interaction is switched off in postcrossing axons via expression of Efnb1, which interacts with Nrp1 [Mire et al., 2018]. The mechanism regulating the timed expression of Efnb1 is not known, but clues can be gained from other commissural systems, for instance where response switching can occur via the cell-intrinsic accumulation of proteins which trigger a switch from attraction to repulsion at a certain threshold of expression [Yam et al., 2012] or where cell-extrinsic cues from midline interaction prompt changes in axonal receptor expression [Yang et al., 2009; Wilson and Stoeckli, 2013].

Finally, the rate of axonal growth is a factor that is intimately linked to the two aforementioned processes, as precocious or delayed interaction between axon and substrate could change final brain connectivity. The rate and dynamics of axonal growth (e.g., pausing, retracting, advancing) change between different cortical areas and axonal tracts [Mouveroux et al., 2000], as well as between

Keeping Time in Cortical Development and Evolution different stages of growth within a single tract [Halloran and Kalil, 1994]. The rate of axonal growth and branching is known to be affected by neuronal activity [Uesaka et al., 2005; Cancedda et al., 2007; Mire et al., 2012] with a higher frequency of calcium transients being associated with faster axonal growth, even within different branches of the same axon [Hutchins and Kalil, 2008]. Electrical activity is also involved in the selection and elimination of axons once cortical axons have begun to innervate their targets [Katz and Shatz, 1996; Mizuno et al., 2007; Wang et al., 2007; Mizuno et al., 2010; Huang et al., 2013; Suárez et al., 2014]. Although a number of molecular players that affect the speed of axon growth have been identified (e.g., RhoA [Dupraz et al., 2019]), the final outcome of varying the speed of cortical axon growth in isolation remains to be fully elucidated.

\section{Timing of Tissue Convergence}

As noted above, the timing of some cellular processes can rely on cell-intrinsic cues, but often the broader context of the developmental environment is crucial for influencing these decisions, for instance by providing physical substrates, or molecular and electrical cues. Although cells born from progenitor cells in the ventricular zone of the cerebral cortex form the main focus of this review, a number of other cell types exist in this region, and the concerted timing of their appearance in the cortex can also critically influence development.

The importance of the appropriately timed convergence of cell and tissue types into the cortex has been experimentally demonstrated by inducing delayed or precocious introductions. For instance, the modification of the migration speed of Cajal-Retzius cells has been shown to change the distribution of each subpopulation across cortical areas, leading to proportional changes in the size of cortical area territories [Barber et al., 2015]. CajalRetzius cells have diverse functions, including correct lamination [Supèr et al., 2000], repolarisation of migrating neurons [Jossin and Cooper, 2011] and the timing of migration termination [Ogawa et al., 1995], but it remains unclear whether and how timing changes influence these functions.

Correctly timed entry of interneurons also has an important influence on developing radial glia and their progeny. A recent study identified Ccp1 as a critical modulator of the "pause and move" cycle of interneuron saltatory migration, and its disruption can significantly decrease pause duration, which in turn results in a transient increase in the number of cortical interneurons invading the cortical plate. This slight change in dynamics of mi- 
gration timing has the effect of increasing the number of proliferating intermediate progenitor cells, thereby also increasing the number of upper layer pyramidal neurons in the mature cortex [Silva et al., 2018].

The speed of growth of developing thalamocortical axons has been shown to rely on spontaneous activity and can therefore be slowed by expression of Kir2.1 in the thalamus, which hyperpolarises neurons [Mire et al., 2012; Castillo-Paterna et al., 2015]. As some of the signals conveyed by thalamocortical axons at these stages are thought to depend on the activity of the sensory system with which they are connected, the correct timing of thalamocortical axon innervation to the cortex also likely depends on the correctly timed and concerted development of the sensory systems. There is a long history of literature showing that disruption of activity from the sensory periphery, or of thalamocortical axons themselves, affects many aspects of cortical development, including the proliferation of progenitor cells [Dehay et al., 2001; Reillo et al., 2010, 2017], as well as cortical architecture, area size, patterning and developmental timing [Dehay et al., 1989; Chou et al., 2013; Fetter-Pruneda et al., 2013; Pouchelon et al., 2014; Moreno-Juan et al., 2017] and corticocortical connectivity [Mizuno et al., 2007; Wang et al., 2007; Mizuno et al., 2010; Huang et al., 2013; Suárez et al., 2014]. Emx2 [López-Bendito et al., 2002] and Sema6a [Leighton et al., 2001] mutant mice display a delay in thalamocortical axon innervation that subsequently recovers, but these mutants nonetheless show altered cortical topography. However, such experimental manipulations have involved either the sustained disruption of cues and/or knockout of genes that have other known roles in cortical cells, and therefore the specific contribution of thalamocortical axon timing to these defects remains unclear. The ongoing emergence of technologies that permit increasingly specific spatial and temporal manipulation will be crucial to identify the distinct influence of different tissues in the developmental milieux of the cortex.

\section{Critical and Sensitive Periods}

Following the appropriate birth, migration, positioning, axon growth and targeting that establishes the broad structure of the neocortex and brain, there is a period of refinement and plasticity that extends into postnatal life and is influenced by emerging sensory experience. The time window during which a developing structure can be altered has come to be known as a "critical period," following Hubel and Wiesel's landmark discoveries in the visual system, whereby kittens visually deprived during a critical period exhibit pronounced alterations in their vi- sual cortex and abnormal sight [Wiesel and Hubel, 1965]. Decades of research since this seminal study have further distinguished between critical periods, during which experience instructs one organisational pattern that is irreversible and irreplaceable for a specific brain function, versus sensitive periods, during which different types of experience can confer many different organisational patterns that tune adult performance to developmental experience [Dehorter and Del Pino, 2020]. An example of the former is the emergence of ocular dominance, whereby depriving binocular neurons of visual input during a critical period results in amblyopia [Fagiolini et al., 1994; Gordon and Stryker, 1996]. An example of the latter is direction preference of visual cortex columns, wherein cells can be more predisposed to firing in response to directions of movement that are experienced during a sensitive developmental period [Li et al., 2008; Van Hooser et al., 2012].

Critical and sensitive periods also extend to other sensory systems, where for instance early sensory input from the whisker pads is required for the appropriate formation of "barrel" structures in the somatosensory cortex [Van der Loos and Woolsey, 1973; Rice and Van Der Loos, 1977]. In the auditory system, early exposure to stimulus complexity tunes the tonotopic organisation and responsiveness of the auditory cortex [de Villers-Sidani et al., 2010; Buran et al., 2014], as well as behavioural preference to sounds [Yang et al., 2012]. Sensory experience also sculpts the long-range connectivity of the cortex, including the corpus callosum [Mizuno et al., 2007; Wang et al., 2007; Mizuno et al., 2010; Huang et al., 2013; Suárez et al., 2014], and temporally constrained periods of patterned network activity have been shown to regulate the timing and extent of neuronal apoptosis [Blanquie et al., 2017; Wong et al., 2018; Duan et al., 2020]. The molecular factors responsible for opening and closing these critical and sensitive periods are still being fully elucidated, but have been shown to involve the extracellular matrix (especially perineuronal nets), synaptic proteins and neurotransmitters [Dehorter and Del Pino, 2020]. A role for sensory experience in permitting, and perhaps even instructing, the development and refinement of brain structure and connectivity during a specific window of time has major implications for timing in development. It means that the time-keeping mechanisms that drive neural development are not only confined to the timing of receptivity during the critical/sensitive period in the brain itself, but also extend to the appropriately timed development of sensory organs, as well as the presentation of sensory experiences to the organism from the external
18

Brain Behav Evol 2022;97:8-32 DOI: $10.1159 / 000521678$
Fenlon 
world. An extreme example of this in humans is the acquisition of language, where if language is not modelled and taught by caregivers during early childhood, it is difficult or impossible to acquire to a complete extent at later stages [Oyama, 1976; Weber-Fox and Neville, 1996; Leonard, 1998].

\section{Time-Keeping Mechanisms in the Cerebral Cortex}

It seems clear that timing is a critical element of many of the modules comprising cortical development and indeed can be an important instructor of cell fate, function and connectivity outcomes. Less well understood is the question of how cells keep time, speed and sequence, and how this translates into differential cellular behaviours and outcomes. Below, the mechanisms of five different possible time-keeping methods are explored as examples.

\section{Cell Cycle}

Following the insight that mouse progenitor cells undergo around 11 divisions, with each division giving rise to a similar identity of neuron [Takahashi et al., 1999], it was postulated that cells could somehow "count" the number of divisions and thereby trigger appropriate cell fate determinants in sequence. However, a recent study that arrested the cell cycle of progenitors found that their temporal progression still continued [Okamoto et al., 2016], indicating that this is not the case. However, as discussed in section 2.1, one aspect of cell cycle that clearly does contribute to cell fate decisions is its length, which increases as development progresses, thereby successively favouring fates towards neurogenesis and away from proliferation. The mechanism for this is thought to involve the "cell cycle length hypothesis", where lengthening the G1 phase allows more time for the action of fatedetermining factors that, for instance, drive neurogenic division, whereas shortening the G1 phase may shield progenitors from the effects of these factors [Calegari and Huttner, 2003]. However, how exactly cells are able to "keep time" to reliably lengthen their cell cycle remains unclear. A recent preprint by Molina et al. [2020] reports that, in the chick spinal cord, rather than specific and coordinated lengthening of individual progenitors, the overall lengthening of the cell cycle at a population level occurs due to an increased heterogeneity of cell cycle length over time [Molina et al., 2020]. The authors compare this finding to work done in epidermal stem cells, where heterogeneity of cell cycle length is linked to the heterogeneity of cell growth [Xie and Skotheim, 2020].
This study set out to explore the relationship between cell size and cell cycle progression in live epidermal stem cells by distinguishing between "adders," in which cells increase in size by a fixed amount each cycle, versus "sizers," in which a threshold of cell size must be reached during G1 before division. This investigation revealed that mammalian epidermal stem cells are "sizers," meaning that when cells are born smaller, they take longer in G1 in order to reach the required threshold size for their next division. If the cortex follows a similar mechanism, then changes in symmetric versus asymmetric division and consequent changes in progeny cell "birth size," as well as changing metabolic pathways contributing to growth rate (e.g., due to progressive maturation/aging of the cortical neurons and/or blood vessels and/or cerebrospinal fluid) could underlie changing cell cycle length [Zappaterra and Lehtinen, 2012; Fawal et al., 2018].

\section{Cell-Intrinsic Regulation}

Although it is unlikely that any cell is able to keep time and respond appropriately without any environmental context, some mechanisms do appear to take place largely cell-intrinsically. For instance, oscillations of mRNA and proteins provide an intriguing means for timed events in the cortex. One of the best described examples of this involves components of the Notch signalling pathway, in particular Hes1 and Dll1, which oscillate alternately with a period of around $2-3 \mathrm{~h}$; this oscillatory activity is crucial for maintaining progenitor status via Hes 1 suppression of proneurogenic bHLH proteins such as Neurog2 and Ascl1 in a dose-dependent manner [Hirata et al., 2002; Shimojo et al., 2008] (Fig. 5a). Hes1 mRNA and protein are particularly unstable, and Hes1 represses its own transcription, which in turn contributes to the oscillatory period [Takebayashi et al., 1994; Hirata et al., 2002]. The cessation of these oscillations coincides with the initiation of neurogenesis, with experimentally precocious cessation of the oscillations inducing premature neurogenesis [Ochi et al., 2020], whereas experimental induction of oscillations via optogenetic constructs can enhance proliferation [Imayoshi et al., 2013]. But how do cells know the right time to stop oscillating and thereby differentiate? It has been shown that miR-9 is intimately involved in regulating these cycles via targeting Hes 1 and Notch2 mRNA, with the long primary transcripts of miR9 (pri-miR-9) cycling out of phase with Hes1. However, in contrast to the unstable Hes 1, miR-9 is very stable and therefore accumulates within cells over time, leading to a progressive dampening of Hes 1 oscillations until an miR9 threshold is reached that stops the oscillations altogeth- 


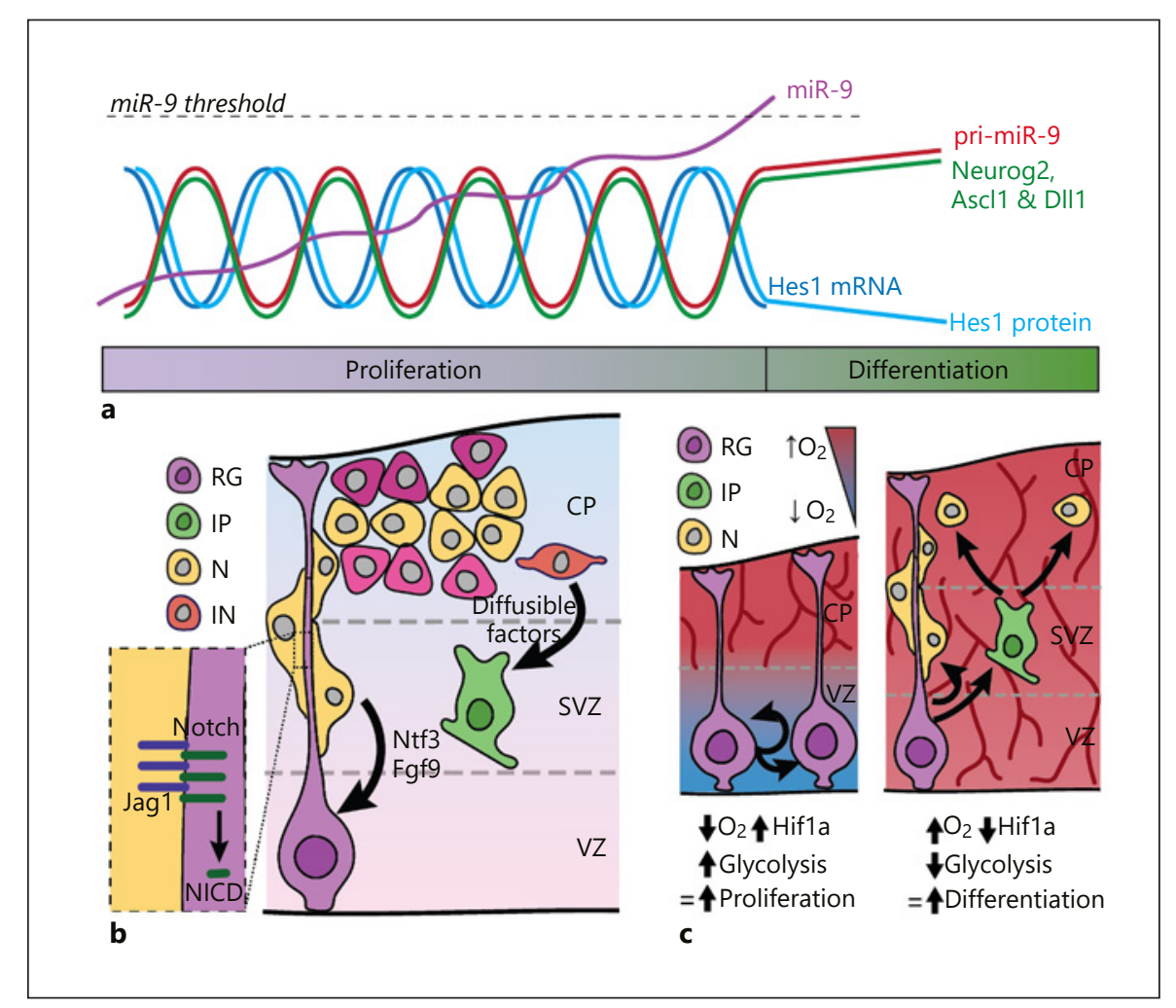

Fig. 5. Schematic representation of three time-keeping mechanisms in the cortex. a An example of a cell-intrinsic mechanism. Oscillations of the unstable Hes1 mRNA and protein are in an alternating cycle with primary transcript (pri)-miR-9, Dll1 and proneurogenic factors. miR-9 is relatively stable, and so accumulates within cells until reaching a threshold that flips cell fate from proliferative to differentiative. b An example of feedback cues from preceding cell types. Apical progenitors (AP) in the ventricular zone (VZ) receive cues from previously born neurons $(\mathrm{N})$ as they migrate to the cortical plate (CP), including Ntf3, Fgf9 and Notch signalling via the release of the Notch intracellular domain (NICD), and intermediate progenitors (IP) in the subventricular zone (SVZ) receive diffusible cues from migrating interneurons (IN), which regulate the balance between proliferation and differentiation. c An example of metabolic processes and oxygen availability. Progressive ingrowth of blood vessels into the ventricular zone (VZ) as an organism ages switches the oxygen availability from low to high, which in turn switches the cell fate from proliferative to differentiative via Hifla signalling and glycolytic activity.

tern, whereby the differentiation of a single neuron consolidates and maintains the progenitor status of its neighbours [Kageyama et al., 2008].

\section{Feedback of Molecular Cues from Surrounding Cells and Tissue}

One of the best understood mechanisms by which tissues keep time is via complex sequences of "domino effects," whereby the successful timed completion of a preceding developmental event elicits a cue that triggers a subsequent developmental event (Fig. 5b). Examples of this include the aforementioned migration of CajalRetzius cells into the cortex, which triggers correct arealisation [Barber et al., 2015] as well as the signalling of invading interneurons to intermediate progenitors, thereby regulating their proliferation [Silva et al., 2018]. 
Newly differentiated neurons also send feedback to remaining apical progenitors, as demonstrated by experiments in which transcription factor Zeb2 (aka Sip1) was deleted from newborn neurons, preventing the release of $\mathrm{Ntf} 3$ and Fgf9 thereby inducing precocious upper layer neuron and glial birth [Seuntjens et al., 2009; Parthasarathy et al., 2014]. In addition, ablating the deep layer neuron population extends the period of deep layer neuron production [Toma et al., 2014]. Similarly, GABA released from invading and maturing interneurons, and glutamate from maturing excitatory neurons, lead to the depolarisation of progenitor cells, alter DNA synthesis, and influence the dynamics of neurogenesis [LoTurco et al., 1995]. Immature neurons and intermediate progenitor cells in the subventricular zone have also been shown to provide feedback to radial glia, via Notch signalling molecules, to regulate the maintenance of the progenitor pool [Yoon et al., 2008; Nelson et al., 2013; Wang et al., 2016]. These data cumulatively show that cues from previously born cells are important for driving the timing and sequence of successive identity generation and maturation.

The cerebrospinal fluid (CSF) is also thought to be a rich source of molecular cues that change over the course of development and influence neural progenitor cells. Experiments growing cortical tissue in vitro with CSF from differently aged animals have shown that the age-dependent CSF proteome has remarkable effects on appropriate growth and survival [Lehtinen and Walsh, 2011; Lehtinen et al., 2011; Fame and Lehtinen, 2020]. Some of the CSFderived factors that have been found to influence progenitor activity in various parts of the brain include Shh [Huang et al., 2010], Lifr [Chau et al., 2015], Fgfs [Lamus et al., 2020], Egfs [Lamus et al., 2020], Wnt-signalling factors [Lehtinen et al., 2011], Igfs [Mairet-Coello et al., 2009; Lehtinen et al., 2011] and Slits [Borrell et al., 2012]. As well as being expressed by the choroid plexus and changing in concentration and availability depending on the ongoing maturation of the ventricular system, some of these cues are expressed by cortical neurons themselves, indicating that the CSF may be involved in the autocrine and paracrine regulation of progenitors.

\section{Electrical Activity and Calcium Waves}

It has recently been shown that ventricular zone progenitors become progressively more hyperpolarised over the period of neurogenesis, and that this has a direct impact on the division mode and laminar and molecular identity of the neurons that are generated [Vitali et al., 2018]. This progressive hyperpolarisation is due to increasing $\mathrm{Ba}^{2+}$-sensitive $\mathrm{K}^{+}$conductance that results in the

Keeping Time in Cortical Development and Evolution inhibition of canonical Wnt signalling. Calcium waves also occur in the developing cortex and can be instigated cell-intrinsically or from external stimuli [Eiraku et al., 2008; Lancaster et al., 2013]. Early cortical progenitors generate spontaneous calcium waves that have a lower frequency and travel less distance than those generated by older cortical progenitors [Owens and Kriegstein, 1998; Weissman et al., 2004; Ackman et al., 2012]. These waves propagate via gap junctions and voltage-gated calcium channels, and their disruption is thought to decrease the proliferative output of progenitors [Malmersjö et al., 2013]. Calcium waves not only influence progenitor cells, but have also been shown to propagate bidirectionally along the apical-basal axis of radial glia, induced by Notch and Fgf signalling, thereby affecting the ongoing neurogenesis of progenitors as well as the migration of postmitotic neurons [Rash et al., 2016]. How progenitor cells translate differential calcium signals into molecular and behavioural changes is not completely clear, but likely involves calcium-activated kinases and phosphatases.

Therefore, the timing dynamics and extent of calcium waves, as well as the electrical activity of progenitors, are likely to be developmental regulators. The mechanisms that regulate the timing and dynamics of this electrical activity remain unclear but likely involve factors such as the timed appropriate connectivity of sensory organs with the cortex, the innervation of thalamocortical axons and their transient synaptic interactions with the subplate, and the availability and distribution of ions in the developing cortex, as well as the progressive addition of new cells to the cortex and their connectivity via gap junctions.

\section{Metabolic Processes and Oxygen Availability}

Recent data have demonstrated that radial glia progressively increase oxidative stress over the course of neurogenesis. Experimentally enhancing oxidative stress by manipulating reactive oxygen species can induce the premature cell cycle exit of radial glia and subsequent changes in cortical organisation, such as an increase in deep layer neurons at the expense of upper layer neurons, whereas reducing reactive oxygen species can rescue this effect [Chui et al., 2020]. Similarly, selective physiological hypoxia of the early avascular ventricular zone is thought to control the expansion of apical progenitor cells, while dense vascularisation of the subventricular zone promotes intermediate progenitor cell expansion [Javaherian and Kriegstein, 2009; Komabayashi-Suzuki et al., 2019]. Appropriately timed ingrowth of blood vessels into the ventricular zone and contact via vascular 
filopodia relieves this physiological hypoxia by providing oxygen, which elicits a switch from proliferation to differentiation, increasing production of both neurons and intermediate progenitor cells. Evidence for this has come from studies using mouse lines with reduced vasculature that show increased apical progenitor proliferation, which can be rescued by increasing oxygen levels, as well as using mouse lines with precocious vascular ingrowth that result in a reduction of apical progenitors and concomitant expansion of basal progenitors [Lange et al., 2016; Komabayashi-Suzuki et al., 2019]. This effect is thought to be mediated by the expression of Hifla when cells are under physiological hypoxia, which in turn enhances glycolytic activity [Lange et al., 2016; Komabayashi-Suzuki et al., 2019] (Fig. 5c). A timed balance between glycolytic metabolism to oxidative phosphorylation is likely to also be involved in regulating the switch between proliferation and differentiation in the mammalian cortex, as has been experimentally shown in the fly [Homem et al., 2014]. Apical progenitor cells in the lateral geniculate nucleus use a similar mechanism and have been shown to actively recruit vascular filipodia by secretion of VEGF-A, which is upregulated during mitosis as well as in response to Hifla, and successful ingrowth triggers cell cycle lengthening, changes in division orientation and increased neurogenesis [Di Marco et al., 2020]. The timing of vascularisation of cortical apical progenitors is likely also regulated by the time spent in the proliferative window, and therefore by the amount of vascular-promoting factors such as VEGF-A and TGF- $\beta_{1}$ released [Siqueira et al., 2018; Komabayashi-Suzuki et al., 2019]. Therefore, the accumulation of reactive oxygen species via metabolic processes, and the progressive increase in the availability of oxygen due to the maturation of the circulatory system, are both processes that could have previously been considered to "passively" occur as an organism grows, with little instructive value. However, emerging evidence suggests that neural progenitor cells participate in the timing of these maturation processes, as well as use the by-products of metabolic growth and aging as clocks to actively instruct appropriately timed cellular events. Indeed, experimentally increasing embryonic brain oxygenation in mouse results in an expanded basal progenitor population that is similar to the outer subventricular zone prominent in gyrencephalic species [Wagenführ et al., 2015], and it is therefore likely that timing and extent of such metabolic processes also constitute potent drivers of evolutionary brain diversity [Wagenführ et al., 2015].

\section{Timing in Brain Phylogeny}

In this section, the existing evidence for evolutionary divergences in developmental timing of the cortex, as well as the mechanisms that might drive such differences, will be discussed. Much of the research on interspecies divergences in cortical development timing have focused on comparing humans with other primates, with the goal of understanding what it is about human development that makes our cerebral cortex "special." However, the principles unearthed by such comparisons thus far can potentially be extrapolated to other examples of evolutionary divergence.

\section{Models of Timing Influencing Species-Specific}

Parameters of Cortical Growth and Architecture

As discussed above, there is substantial evidence that the timing, speed and sequence of developmental events within a species are important regulators of the phenotypic outcome of the cerebral cortex. However, what is the evidence that timing is a factor that changes with the evolution of species to produce divergent forms and functions of the cerebral cortex? Barbara Finlay's group has been refining a model over several years that can predict the timing of 271 neurodevelopmental events in mammals. With the exception of the slower metatherians, the rate of progression through this event scale is highly correlated with adult brain size. However, significant lineage-specific heterochronies for the neocortex have been found, whereby non-glires mammals show a delay in corticogenesis, which in turn is associated with a relatively larger adult cortex [Clancy et al., 2001; Workman et al., 2013]. Other models have identified peak brain growth velocity as an excellent predictor of brain size [Halley, 2017] and have explained diversity in cortical neuron number across mammals in terms of variations in three parameters, cell cycle rate, progenitor death rate and the "quit rate" aka ratio of terminal divisions [Cahalane et al., 2014 ], or by choosing a combination of progenitor lineage, number of founder cells and neurogenic period length [Lewitus et al., 2014]. This latter work found a correlation between the number of neocortical neurons observed in six primate species and the length of the neurogenic period. Similarly, the final number of cortical neurons can be predicted with the parameters of founder population size, duration of neurogenesis, proportion of different progenitor types, and balance between self-renewing and differentiative divisions, with this approach being used to accurately model experimentally observed patterns of neurogenesis in the mouse, macaque and hu- 
man. The resultant model predicts that the timing of the switch from proliferative to neurogenic divisions produces the highest variation in final cortical numbers and is therefore potentially a strong driver of final brain morphology between species [Picco et al., 2018]. It is therefore clear that the timing and kinetics of neurogenesis vary across extant species, and that these changes correlate with altered brain morphology [Iwata, 2021; Stepien et al., 2021]. The causative role of these relationships can be inferred from experimental manipulations within the mouse, e.g. where extending the period of neurogenesis results in a larger cortex [Stepien et al., 2020].

\section{Timing of Cellular Processes among Species}

Notable Examples of Interspecies Differences

From the above modelling studies, it is clear that, at a gross level, cortical development is slower in primates compared to mice, as well as in humans compared to nonhuman primates, and that these dynamics correlate with altered cortical morphology. But which cellular processes contribute to these overarching developmental rates? In vivo studies using cell birth-dating have shown that cell cycle length is longer in monkeys [Caviness et al., 1995; Kornack and Rakic, 1998; Lukaszewicz et al., 2005] than in mice [Takahashi et al., 1995]. Cortical expansion throughout evolution generally correlates with the preferential expansion of superficial layers of the cortex, with upper layer neurons comprising a greater proportion of the adult cortex of primates compared with carnivores, and of carnivores compared with rodents [Hutsler et al., 2005]. This expansion is linked with an extension of the period of neurogenesis [Caviness et al., 1995; Rakic, 1995; Kriegstein et al., 2006], especially the end of neurogenesis, which would allow the continuation of upper layer neuron production. Humans and non-human primates do not display stark differences in the proportion of cortical layers [Hutsler et al., 2005; de Sousa et al., 2009], and it has therefore been hypothesised that human-specific cortical expansion may instead be driven by changes in the timing of processes at the beginning of the neurogenic window. Recent studies using organoids have been able to shed light on this issue, with reports that human progenitor cells display a longer $\mathrm{S}$ phase than those of chimpanzees [Mora-Bermúdez et al., 2016] and a shorter overall cell cycle compared to gorillas [Benito-Kwiecinski et al., 2021]. Human organoids and induced excitatory neurons generally mature at a slower pace than non-human primate organoids, and neurogenesis commences later [Otani et al., 2016; Schörnig et al., 2021]. The delayed commencement of neurogenesis is accompanied by a delayed neuroepithe-

Keeping Time in Cortical Development and Evolution lial cell to radial glial transition relative to apes, thereby allowing more time for neuroepithelial progenitors to proliferate and expand the founder pool prior to the onset of neurogenesis [Benito-Kwiecinski et al., 2021]. The same study also identified different dynamics of Zeb2 (Sip1), the RNA expression of which peaks earlier in ape compared to human organoids, as a key regulator of this transition. Manipulation of this gene pathway could alter the timing of the transition between cell types and thereby phenocopy the cortical architecture of other species. The delay in the onset of neurogenesis postulated to underlie the greater brain expansion in primates relative to rodents [Rakic, 1995] is not unique to the cerebral cortex of mammals, as larger-brained birds also show developmentally delayed neurogenesis compared to those with a smaller brain [Charvet and Striedter, 2008].

To examine the relative rates of processes following neurogenesis, xenotransplants of induced pluripotent stem cells derived from humans and chimpanzees have been transplanted into the mouse cortex to reveal that human neurons migrate more slowly than those of the chimpanzee, and are slower to reach milestones of maturity (such as firing rates) [Linaro et al., 2019; Marchetto et al., 2019]. Similarly, human induced pluripotent stem cells take longer to differentiate than rodent neurons, as well as having a slower rate of axonal elongation [Ohara et al., 2015] and a longer period of postmitotic fate plasticity [Iwata et al., 2020]. Thalamocortical afferents innervate the subplate earlier in primates than in rodents, suggesting that the timing of cortical exposure to extracortical factors may also be evolutionarily relevant [Alzu'bi et al., 2019]. RNA sequencing of human versus non-human primate organoids or tissue have revealed a general trend towards earlier expression and a steeper rate of increasing expression of genes that are related to mature processes, such as synaptic formation and maturation, in non-human primates [Liu et al., 2012; Mora-Bermúdez et al., 2016; Kanton et al., 2019; Marchetto et al., 2019; Pollen et al., 2019; Benito-Kwiecinski et al., 2021; Schörnig et al., 2021]. This may be a phenomenon specific to the cortex, as other brain regions such as the cerebellum do not exhibit the same trends [Liu et al., 2012]. For example, the expression of synaptic genes in the human prefrontal cortex peaks 1 year postnatally in chimpanzees and macaques, whereas this occurs at 5 years of age in humans. Observations of synaptic density support these transcriptomic findings, suggesting that dynamic processes of overproduction and developmental remodelling of synaptic spines can continue as far as the third decade of human life [Petanjek et al., 2011; Liu et al., 2012; Linaro et 
al., 2019]. The different time courses of cellular processes between species often appear to have both cell-intrinsic and -extrinsic components. For instance, pluripotent stem cells from humans and mice show rates of differentiation that closely reflect their normal rates of progression in vivo [Barry et al., 2017], but these set rates of development can also be influenced if they are cocultured with cells from another species [Brown et al., 2021]. Therefore, no single cellular process is reliably altered in timing between different species with divergent cortical morphology. This could point to one of two options: (1) the timing of myriad different processes is subject to evolutionary change, often in concert with one another or (2) alternatively, few select processes are directly changed, and they in turn precede and influence the timing of subsequent developmental events. Further studies linking the timing of developmental subprocesses with subsequent events and adult form in the cortex of different species, as well as via experimental manipulation within species, will be helpful to better understand this topic.

\section{Experimental Demonstration that Timing}

Differences Affect Species-Specific Complex Traits

Although many correlations have been made between the differential timing of the expression of genes and proteins between species and diverse morphological outcomes, very few experimental demonstrations of the causative agency of these to elicit changes in complex traits have been reported. A recent study addressed this by experimentally manipulating the timing of expression of a key transcription factor that regulates neuronal identity and projection fate: Satb2 [Paolino et al., 2020]. Satb2 is expressed in neurons that ultimately form the corpus callosum, and it in turn represses Bcl11b, which specifies a subcerebral projection fate. Given that marsupials do not have a corpus callosum, with their interhemispheric corticocortical connections instead projecting through the anterior commissure [Suárez et al., 2018], the study investigated the expression of Satb2 in a marsupial model. Surprisingly, the sequence, cell-type specific expression and function of Satb2 were remarkably conserved between eutherian and marsupial animals. However, the Satb2 protein showed a precocious initiation of expression in marsupials. Phenocopying this earlier pattern of expression in the mouse resulted in projection neurons taking a more "marsupial-like" projection route through the anterior commissure. This study highlights the potential of small changes in the timing of a single and otherwise conserved gene to produce remarkable anatomical changes in a developing brain.

\section{Mechanisms Driving Evolutionary Changes in \\ Developmental Timing in the Cortex}

Major Drivers of Differential Gene Expression Timing

Not only are the kinetics of individual cellular processes different between species, but there are also notable changes in gene expression, for instance a bias towards delays in gene expression in humans compared to apes, a phenomenon termed "transcriptional neoteny" [Somel et al., 2009; Li et al., 2020]. A potential primary mechanism driving these differences was suggested by Somel et al. [2011], who found that, when compared to chimpanzees and macaques, humans have a more rapidly changing pattern of developmental gene expression than genomic divergences [Somel et al., 2011]. These changes in developmental gene expression were found to be brain-areaspecific, for instance occurring 5 times more frequently in the prefrontal cortex than the cerebellum, as well as primarily driven by transregulatory changes such as microRNAs and transcription factors. Therefore, major changes in the timing and sequence of developmental gene expression likely predominantly arise from changes in a few central transregulators that are upstream of (and therefore change in concert) hundreds of putative targets that are relatively conserved in sequence and function.

\section{Genome Divergence Influences the Timing of}

\section{Processes}

Despite the above findings, there have also been studies that show that species-specific cis-regulatory or protein coding sequences of a single non-transcription factor gene can change the dynamics of neurogenesis [Suzuki, 2020; Pinson and Huttner, 2021]. For instance, the human-specific enhancer region of FZD8 accelerates the cell cycle and leads to a larger neocortex than the chimpanzee-specific enhancer region when ectopically transfected into the mouse [Boyd et al., 2015]. Gene duplication has long been posited to be a driving force in evolutionary variance, by duplicating genes that can then undergo mutations to produce varying form and functions [Ohno, 1970]. One elegant example of this showed that NOTCH2NL has a copy number variant that is particularly increased in humans and promotes the extension of the neurogenic period and thereby expanded cortical volume [Fiddes et al., 2018; Suzuki et al., 2018]. Overexpression of the human-specific ARHGAP11B in the mouse, ferret or marmoset also results in a larger basal radial glia population, protracted timing of neurogenesis and consequently a larger cortex with more complex folding patterns that persists into adulthood and increases cognitive abilities such as memory flexibility [Florio et al., 2015, 2016; Kalebic et al., 2018; Heide et al., 2020; Xing et al., 
2021]. Overexpression of human-specific SRGAP2C can extend the period of neurogenesis and inhibit spine maturation [Charrier et al., 2012; Fossati et al., 2016]. Therefore, although broad patterns of transcriptional heterochrony (such as human transcriptional neotony) are likely driven by alterations of a handful of central transregulators, species-specific changes in cis-regulatory or protein-coding regions of single genes can also impact the timing of developmental processes and consequently the form and function of the cerebral cortex.

\section{Conclusion}

The onset, offset, duration, speed and sequence of developmental events often permit, and in many cases instruct, numerous elements of the final architecture, connectivity and function of the neocortex. Small changes in the timing of these processes are increasingly thought to be important for understanding the mechanisms of cortical development, as well as of potential disease pathologies [Marín, 2016]. As ontogeny proceeds, developmental processes, as well as the ultimate brain functions they subserve, become increasingly complex and interdependent. Many of the clearest examples of the role of timing in driving neocortical ontogeny and phylogeny have therefore come from studies of early processes, such as cell cycle, due to the relatively limited number of factors that influence them. However, timing may be even more crucial for later complex processes and functions, due to the need for many internal and external instructive influences to converge. An intriguing example of a highly complex function is human social development, which is disrupted in autism spectrum disorders. A confluence of genetic and environmental factors influences the emergence and severity of autism spectrum disorders, including a temporary shift in the neurotransmitter GABA from depolarising to hyperpolarising neurons during birth. The timing of this shift, as well as other critical/sensitive periods, is disrupted in mouse models of autism spectrum disorders, and its experimental disruption causes social deficits in wild-type mice [Tyzio et al., 2014]. The role of this event is still not fully understood, but it likely depends upon the timed confluence of factors from the birth process, such as levels of oxytocin and appropriate maternal immune system function [Fernandez et al., 2019], as well as itself permitting a critical or sensitive period in brain development during which other internal and external cues can take effect. The possibility of reopening such critical/sensitive periods in adulthood is therefore a rapidly expanding area

Keeping Time in Cortical Development and Evolution of interest for the treatment of neurodevelopmental disorders [Marín, 2016; Dehorter and Del Pino, 2020].

It is also becoming increasingly clear that the timing of maturation of other bodily systems such as the circulatory system and the sensory organs, as well as the availability of metabolites and nutrients and basal metabolic rates, crucially influences the timing and sequence of development in the brain. This is likely to be of particular importance within evolution, where developmental constraints on timing in other bodily systems may have indirectly influenced brain evolution and morphology. An intriguing example of this is the comparison between the extreme premature birth of marsupial mammals, necessitating advanced maturation of the jaw, forelimbs and likely olfactory system prior to the onset of most neocortical development, and the extended placentation of eutherian mammals, which allows a delay in these processes. A shift in thinking away from the modern tendency to attribute developmental and evolutionary change to a single gene, and back to the systems-level approach founded by Aristotle's concept of epigenesis, will be crucial to fully understand the role of timing in whole organismal ontogeny. Indeed, the recent advent of single-cell RNAseq, as well as temporally and spatially controlled gene-editing technologies, is already allowing a more complex characterisation and manipulation of cells over time than has previously been possible, and will no doubt rapidly accelerate this field in the coming years.

\section{Acknowledgements}

Thanks go to Rodrigo Suárez, Annalisa Paolino, Stefan Thor, Zorana Lynton, Rowan Tweedale, Uli Siebeck and anonymous reviewers for valuable discussions and feedback.

\section{Conflict of Interest Statement}

The author has no conflicts of interest to declare.

\section{Funding Sources}

This work was supported by an Australian Research Council (ARC) Discovery Project Grant DP200103093 and a National Health and Medical Research Council (NHMRC) Investigator Grant 1175825.

\section{Author Contributions}

L.R.F. conceived of, researched and wrote the article. 


\section{References}

Ackman JB, Burbridge TJ, Crair MC. Retinal waves coordinate patterned activity throughout the developing visual system. Nature. 2012;490(7419):219-25.

Alsiö JM, Tarchini B, Cayouette M, Livesey FJ. Ikaros promotes early-born neuronal fates in the cerebral cortex. Proc Natl Acad Sci U S A. 2013;110(8):E716-25.

Alzu'bi A, Homman-Ludiye J, Bourne JA, Clowry GJ. Thalamocortical afferents innervate the cortical subplate much earlier in development in primate than in rodent. Cereb Cortex. 2019;29(4):1706-18.

Angevine JB, Sidman RL. Autoradiographic study of cell migration during histogenesis of cerebral cortex in the mouse. Nature. 1961 Nov; 192(4804):766-8

Arai Y, Pulvers JN, Haffner C, Schilling B, Nüsslein I, Calegari F, et al. Neural stem and progenitor cells shorten S-phase on commitment to neuron production. Nat Commun. 2011 Jan;2(1):154.

Azim E, Shnider SJ, Cederquist GY, Sohur US Macklis JD. Lmo4 and Clim1 progressively delineate cortical projection neuron subtypes during development. Cereb Cortex. 2009 Jul; 19 Suppl 1:i62-9.

Barber M, Arai Y, Morishita Y, Vigier L, Causeret F, Borello U, et al. Migration speed of CajalRetzius cells modulated by vesicular trafficking controls the size of higher-order cortical areas. Curr Biol. 2015 Oct;25(19):2466-78.

Barber M, Pierani A. Tangential migration of glutamatergic neurons and cortical patterning during development: lessons from CajalRetzius cells. Dev Neurobiol. 2016 Aug;76(8): $847-81$.

Barnabé-Heider F, Wasylnka JA, Fernandes KJ, Porsche C, Sendtner M, Kaplan DR, et al. Evidence that embryonic neurons regulate the onset of cortical gliogenesis via cardiotrophin-1. Neuron. 2005 Oct;48(2):253-65.

Barry C, Schmitz MT, Jiang P, Schwartz MP, Duffin BM, Swanson S, et al. Species-specific developmental timing is maintained by pluripotent stem cells ex utero. Dev Biol. 2017 Mar; 423(2):101-10.

Benito-Kwiecinski S, Giandomenico SL, Sutcliffe M, Riis ES, Freire-Pritchett P, Kelava I, et al. An early cell shape transition drives evolutionary expansion of the human forebrain. Cell. 2021 Mar;184(8):2084-102.e19.

Bielas S, Higginbotham H, Koizumi H, Tanaka T, Gleeson JG. Cortical neuronal migration mutants suggest separate but intersecting pathways. Annu Rev Cell Dev Biol. 2004;20(1) 593-618.

Bielle F, Griveau A, Narboux-Nême N, Vigneau S, Sigrist M, Arber S, et al. Multiple origins of Cajal-Retzius cells at the borders of the developing pallium. Nat Neurosci. 2005 Aug;8(8) 1002-12.
Blanquie O, Yang JW, Kilb W, Sharopov S, Sinning A, Luhmann HJ. Electrical activity controls area-specific expression of neuronal apoptosis in the mouse developing cerebral cortex. eLife. 2017 Aug;6:e27696.

Bonev B, Stanley P, Papalopulu N. MicroRNA-9 modulates Hes1 ultradian oscillations by forming a double-negative feedback loop. Cell Rep. 2012 Jul;2(1):10-8.

Borrell V, Cárdenas A, Ciceri G, Galcerán J, Flames N, Pla R, et al. Slit/Robo signaling modulates the proliferation of central nervous system progenitors. Neuron. $2012 \mathrm{Oct}$; 76(2):338-52.

Boyd JL, Skove SL, Rouanet JP, Pilaz LJ, Bepler T, Gordân R, et al. Human-chimpanzee differences in a FZD8 enhancer alter cell-cycle dynamics in the developing neocortex. Curr Biol. 2015 Mar;25(6):772-79.

Britanova O, de Juan Romero C, Cheung A, Kwan KY, Schwark M, Gyorgy A, et al. Satb2 is a postmitotic determinant for upper-layer neuron specification in the neocortex. Neuron. 2008;57(3):378-92.

Brown J, Barry C, Schmitz MT, Argus C, Bolin JM, Schwartz MP, et al. Interspecies chimeric conditions affect the developmental rate of human pluripotent stem cells. PLoS Comput Biol. 2021;17(3):e1008778.

Buchsbaum IY, Cappello S. Neuronal migration in the CNS during development and disease: insights from in vivo and in vitro models. Development. 2019;146(1):dev163766.

Buran BN, Sarro EC, Manno FA, Kang R, Caras ML, Sanes DH. A sensitive period for the impact of hearing loss on auditory perception. J Neurosci. 2014;34(6):2276-84.

Cahalane DJ, Charvet CJ, Finlay BL. Modeling local and cross-species neuron number variations in the cerebral cortex as arising from a common mechanism. Proc Natl Acad Sci U S A. 2014;111(49):17642-7.

Calegari F, Haubensak W, Haffner C, Huttner WB. Selective lengthening of the cell cycle in the neurogenic subpopulation of neural progenitor cells during mouse brain development. J Neurosci. 2005 Jul;25(28):6533-8.

Calegari F, Huttner WB. An inhibition of cyclindependent kinases that lengthens, but does not arrest, neuroepithelial cell cycle induces premature neurogenesis. J Cell Sci. 2003; 116(24):4947-55.

Cancedda L, Fiumelli H, Chen K, Poo MM. Excitatory GABA action is essential for morphological maturation of cortical neurons in vivo. J Neurosci. 2007 May;27(19):5224-35.

Castillo-Paterna M, Moreno-Juan V, Filipchuk A, Rodríguez-Malmierca L, Susín R, López-Bendito G. DCC functions as an accelerator of thalamocortical axonal growth downstream of spontaneous thalamic activity. EMBO Rep. 2015 Jul;16(7):851-62.
Caviness VS Jr, Goto T, Tarui T, Takahashi T, Bhide PG, Nowakowski RS. Cell output, cell cycle duration and neuronal specification: a model of integrated mechanisms of the neocortical proliferative process. Cereb Cortex. 2003;13(6):592-8.

Caviness VS Jr, Takahashi T, Nowakowski RS. Numbers, time and neocortical neuronogenesis: a general developmental and evolutionary model. Trends Neurosci. 1995 Sep;18(9): $379-83$.

Charrier C, Joshi K, Coutinho-Budd J, Kim J-E, Lambert N, de Marchena J, et al. Inhibition of SRGAP2 function by its human-specific paralogs induces neoteny during spine maturation. Cell. 2012;149(4):923-35.

Charvet CJ, Striedter GF. Developmental species differences in brain cell cycle rates between northern bobwhite quail (Colinus virginianus) and parakeets (Melopsittacus undulatus): implications for mosaic brain evolution. Brain Behav Evol. 2008;72(4):295-306.

Chau KF, Springel MW, Broadbelt KG, Park HY, Topal S, Lun MP, et al. Progressive differentiation and instructive capacities of amniotic fluid and cerebrospinal fluid proteomes following neural tube closure. Dev Cell. 2015 Dec;35(6):789-802.

Chen B, Wang SS, Hattox AM, Rayburn H, Nelson SB, McConnell SK. The Fezf2-Ctip2 genetic pathway regulates the fate choice of subcortical projection neurons in the developing cerebral cortex. Proc Natl Acad Sci U S A. 2008;105(32):11382-7.

Chenn A, Walsh CA. Regulation of cerebral cortical size by control of cell cycle exit in neural precursors. Science. 2002 Jul;297(5580):365-

Chew KY, Shaw G, Yu H, Pask AJ, Renfree MB Heterochrony in the regulation of the developing marsupial limb. Dev Dyn. 2014 Feb; 243(2):324-38

Choe Y, Huynh T, Pleasure SJ. Migration of oligodendrocyte progenitor cells is controlled by transforming growth factor $\beta$ family proteins during corticogenesis. J Neurosci. 2014; 34(45):14973-83

Chou SJ, Babot Z, Leingärtner A, Studer M, Nakagawa Y, O'Leary DD. Geniculocortical input drives genetic distinctions between primary and higher-order visual areas. Science. 2013 Jun;340(6137):1239-42.

Chui A, Zhang Q, Dai Q, Shi SH. Oxidative stress regulates progenitor behavior and cortical neurogenesis. Development. 2020;147(5): $\operatorname{dev} 184150$.

Clancy B, Darlington RB, Finlay BL. Translating developmental time across mammalian species. Neuroscience. 2001;105(1):7-17.

Cooper JA. Molecules and mechanisms that regulate multipolar migration in the intermediate zone. Front Cell Neurosci. 2014;8:386-86.

Davis AA, Temple S. A self-renewing multipotential stem cell in embryonic rat cerebral cortex. Nature. 1994 Nov;372(6503):263-6. 
De Beer G. Embryos and ancestors. Oxford: Clarendon Press; 1940. p. 108.

de Sousa AA, Sherwood CC, Schleicher A, Amunts K, MacLeod CE, Hof PR, et al. Comparative cytoarchitectural analyses of striate and extrastriate areas in hominoids. Cereb Cortex. 2009;20(4):966-81.

de Villers-Sidani E, Alzghoul L, Zhou X, Simpson KL, Lin RC, Merzenich MM. Recovery of functional and structural age-related changes in the rat primary auditory cortex with operant training. Proc Natl Acad Sci U S A. 2010; 107(31):13900-5

Dehay C, Horsburgh G, Berland M, Killackey H, Kennedy H. Maturation and connectivity of the visual cortex in monkey is altered by prenatal removal of retinal input. Nature. 1989 Jan;337(6204):265-7.

Dehay C, Savatier P, Cortay V, Kennedy H. Cellcycle kinetics of neocortical precursors are influenced by embryonic thalamic axons. J Neurosci. 2001;21(1):201-14.

Dehorter N, Del Pino I. Shifting developmental trajectories during critical periods of brain formation. Front Cell Neurosci. 2020 Sep; 14(283):283.

Del Toro D, Ruff T, Cederfjäll E, Villalba A, SeyitBremer G, Borrell V, et al. Regulation of cerebral cortex folding by controlling neuronal migration via FLRT adhesion molecules. Cell. 2017 May;169(4):621-35.e16.

Desai AR, McConnell SK. Progressive restriction in fate potential by neural progenitors during cerebral cortical development. Development. 2000 Jul;127(13):2863-72.

Di Marco B, Crouch EE, Shah B, Duman C, Paredes MF, Ruiz de Almodovar C, et al. Reciprocal interaction between vascular filopodia and neural stem cells shapes neurogenesis in the ventral telencephalon. Cell Rep. 2020 Oct; 33(2): 108256

Duan ZRS, Che A, Chu P, Modol L, Bollmann Y, Babij R, et al. GABAergic restriction of network dynamics regulates interneuron survival in the developing cortex. Neuron. 2020 Jan; 105(1):75-92.e5.

Dupraz S, Hilton BJ, Husch A, Santos TE, Coles $\mathrm{CH}$, Stern S, et al. RhoA controls axon extension independent of specification in the developing brain. Curr Biol. 2019 Nov;29(22): 3874-86.e9.

Eiraku M, Watanabe K, Matsuo-Takasaki M, Kawada M, Yonemura S, Matsumura M, et al. Self-organized formation of polarized cortical tissues from ESCs and its active manipulation by extrinsic signals. Cell Stem Cell. 2008;3(5): 519-32.

Ellender TJ, Avery SV, Mahfooz K, Scaber J, von Klemperer A, Nixon SL, et al. Embryonic progenitor pools generate diversity in fine-scale excitatory cortical subnetworks. Nat Commun. 2019 Nov;10(1):5224.
Englund C, Fink A, Lau C, Pham D, Daza RAM, Bulfone A, et al. Pax6, Tbr2, and Tbr1 are expressed sequentially by radial glia, intermediate progenitor cells, and postmitotic neurons in developing neocortex. J Neurosci. 2005; 25(1):247-51.

Fagiolini M, Pizzorusso T, Berardi N, Domenici L, Maffei L. Functional postnatal development of the rat primary visual cortex and the role of visual experience: dark rearing and monocular deprivation. Vision Res. 1994; 34(6):709-20.

Fame RM, Lehtinen MK. Emergence and developmental roles of the cerebrospinal fluid system. Dev Cell. 2020 Feb;52(3):261-75.

Faux C, Rakic S, Andrews W, Britto JM. Neurons on the move: migration and lamination of cortical interneurons. Neurosignals. 2012; 20(3):168-89.

Fawal MA, Jungas T, Kischel A, Audouard C, Iacovoni JS, Davy A. Cross talk between onecarbon metabolism, Eph signaling, and histone methylation promotes neural stem cell differentiation. Cell Rep. 2018 Jun;23(10): 2864-73.e7

Fernandez A, Dumon C, Guimond D, Tyzio R, Bonifazi P, Lozovaya N, et al. The GABA developmental shift Is abolished by maternal immune activation already at birth. Cereb Cortex. 2019 Aug;29(9):3982-92.

Fetter-Pruneda I, Geovannini-Acuña H, Santiago C, Ibarrarán-Viniegra AS, Martínez-Martínez E, Sandoval-Velasco M, et al. Shifts in developmental timing, and not increased levels of experience-dependent neuronal activity, promote barrel expansion in the primary somatosensory cortex of rats enucleated at birth. PLoS One. 2013;8(1):e54940.

Fiddes IT, Lodewijk GA, Mooring M, Bosworth CM, Ewing AD, Mantalas GL, et al. Humanspecific NOTCH2NL genes affect notch signaling and cortical neurogenesis. Cell. 2018 May;173(6):1356-69.e22.

Fietz SA, Kelava I, Vogt J, Wilsch-Bräuninger M, Stenzel D, Fish JL, et al. OSVZ progenitors of human and ferret neocortex are epithelial-like and expand by integrin signaling. Nat Neurosci. 2010 Jun;13(6):690-9.

Florio M, Albert M, Taverna E, Namba T, Brandl $\mathrm{H}$, Lewitus E, et al. Human-specific gene ARHGAP11B promotes basal progenitor amplification and neocortex expansion. Science. 2015 Mar;347(6229):1465-70.

Florio M, Huttner WB. Neural progenitors, neurogenesis and the evolution of the neocortex. Development. 2014;141(11):2182-94.

Florio M, Namba T, Pääbo S, Hiller M, Huttner WB. A single splice site mutation in humanspecific ARHGAP11B causes basal progenitor amplification. Sci Adv. 2016;2(12):e1601941.

Fossati M, Pizzarelli R, Schmidt ER, Kupferman JV, Stroebel D, Polleux F, et al. SRGAP2 and its human-specific paralog co-regulate the development of excitatory and inhibitory synapses. Neuron. 2016 Jul;91(2):356-69.
Franco SJ, Gil-Sanz C, Martinez-Garay I, Espinosa A, Harkins-Perry SR, Ramos C, et al. Faterestricted neural progenitors in the mammalian cerebral cortex. Science. 2012;337(6095): 746-49.

Gal JS, Morozov YM, Ayoub AE, Chatterjee M, Rakic P, Haydar TF. Molecular and morphological heterogeneity of neural precursors in the mouse neocortical proliferative zones. J Neurosci. 2006 Jan;26(3):1045-56.

Gao P, Postiglione MP, Krieger TG, Hernandez L, Wang C, Han Z, et al. Deterministic progenitor behavior and unitary production of neurons in the neocortex. Cell. 2014 Nov; 159(4): $775-88$.

García-Moreno F, Molnár Z. Subset of early radial glial progenitors that contribute to the development of callosal neurons is absent from avian brain. Proc Natl Acad Sci U S A. 2015 Sep;112(36):E5058-67.

García-Moreno F, Molnár Z. Chapter 25: the impact of different modes of neuronal migration on brain evolution. In: Rubenstein J, Rakic $\mathrm{P}$, Chen B, Kwan KY, Kolodkin A, Anton E, editors. Cellular migration and formation of axons and dendrites. 2nd ed. Cambridge: Academic Press; 2020. p. 555-76.

Georgopoulou N, Hurel C, Politis PK, Gaitanou M, Matsas R, Thomaidou D. BM88 is a dual function molecule inducing cell cycle exit and neuronal differentiation of neuroblastoma cells via cyclin D1 down-regulation and retinoblastoma protein hypophosphorylation. J Biol Chem. 2006;281(44):33606-20.

Gertz CC, Lui JH, LaMonica BE, Wang X, Kriegstein AR. Diverse behaviors of outer radial glia in developing ferret and human cortex. J Neurosci. 2014;34(7):2559-70.

Ginhoux F, Prinz M. Origin of microglia: current concepts and past controversies. Cold Spring Harb Perspect Biol. 2015;7(8):a020537-37.

Gobius I, Morcom L, Suárez R, Bunt J, Bukshpun $\mathrm{P}$, Reardon W, et al. Astroglial-mediated remodeling of the interhemispheric midline Is required for the formation of the corpus callosum. Cell Rep. 2016;17(3):735-47.

Gobius I, Richards L. Creating connections in the developing brain: mechanisms regulating corpus callosum development. Colloquium Series Dev Brain. 2011 Jul;2(1):1-48.

Gobius I, Suarez R, Morcom L, Paolino A, Edwards TJ, Kozulin P, et al. Astroglial-mediated remodeling of the interhemispheric midline during telencephalic development is exclusive to eutherian mammals. Neural Dev. 2017 May;12(1):9.

Goodfellow M, Phillips NE, Manning C, Galla T, Papalopulu N. microRNA input into a neural ultradian oscillator controls emergence and timing of alternative cell states. Nat Commun. 2014 Mar;5(1):3399.

Gordon JA, Stryker MP. Experience-dependent plasticity of binocular responses in the primary visual cortex of the mouse. J Neurosci. 1996 May;16(10):3274-86. 
Gorski JA, Talley T, Qiu M, Puelles L, Rubenstein JL, Jones KR. Cortical excitatory neurons and glia, but not GABAergic neurons, are produced in the Emx1-expressing lineage. J Neurosci. 2002;22(15):6309-14.

Götz M, Huttner WB. The cell biology of neurogenesis. Nat Rev Mol Cell Biol. 2005 Oct; 6(10):777-88

Gould SJ. Ontogeny and phylogeny. Cambridge: Harvard University Press; 1977.

Guo C, Eckler MJ, McKenna WL, McKinsey GL, Rubenstein JL, Chen B. Fezf2 expression identifies a multipotent progenitor for neocortical projection neurons, astrocytes, and oligodendrocytes. Neuron. 2013;80(5):1167-74.

Halley AC. Minimal variation in eutherian brain growth rates during fetal neurogenesis. Proc Biol Sci. 2017 May;284:284.

Halloran MC, Kalil K. Dynamic behaviors of growth cones extending in the corpus callosum of living cortical brain slices observed with video microscopy. J Neurosci. 1994 14(4):2161-77.

Hanashima C, Li SC, Shen L, Lai E, Fishell G Foxg1 suppresses early cortical cell fate. Science. 2004 Jan;303(5654):56-9.

Hansen AH, Duellberg C, Mieck C, Loose M, Hippenmeyer S. Cell polarity in cerebral cortex development-cellular architecture shaped by biochemical networks. Front Cell Neurosci. 2017;11:176-76.

Hansen DV, Lui JH, Parker PR, Kriegstein AR. Neurogenic radial glia in the outer subventricular zone of human neocortex. Nature. 2010 Mar;464(7288):554-61.

Hatakeyama J, Bessho Y, Katoh K, Ookawara S, Fujioka M, Guillemot F, et al. Hes genes regulate size, shape and histogenesis of the nervous system by control of the timing of neural stem cell differentiation. Development. 2004 Nov;131(22):5539-50.

Hatanaka Y, Namikawa T, Yamauchi K, Kawaguchi Y. Cortical divergent projections in mice originate from two sequentially generated, distinct populations of excitatory cortical neurons with different initial axonal outgrowth characteristics. Cereb Cortex. 2015 26(5):2257-70

Haubensak W, Attardo A, Denk W, Huttner WB. Neurons arise in the basal neuroepithelium of the early mammalian telencephalon: a major site of neurogenesis. Proc Natl Acad Sci U S A. 2004;101(9):3196-201.

Haydar TF, Ang E, Rakic P. Mitotic spindle rotation and mode of cell division in the developing telencephalon. Proc Natl Acad Sci U S A. 2003;100(5):2890-5.

He F, Ge W, Martinowich K, Becker-Catania S, Coskun V, Zhu W, et al. A positive autoregulatory loop of Jak-STAT signaling controls the onset of astrogliogenesis. Nat Neurosci. 2005 May;8(5):616-25.

He L, Jones J, He W, Bjork BC, Wen J, Dai Q. PRDM16 regulates a temporal transcriptional program to promote progression of cortical neural progenitors. Development. 2021 Mar; 17(6):148
Heide M, Haffner C, Murayama A, Kurotaki Y, Shinohara H, Okano H, et al. Human-specific ARHGAP11B increases size and folding of primate neocortex in the fetal marmoset. Science. 2020;369(6503):546-50.

Hirabayashi Y, Suzuki N, Tsuboi M, Endo TA, Toyoda T, Shinga J, et al. Polycomb limits the neurogenic competence of neural precursor cells to promote astrogenic fate transition. Neuron. 2009 Sep;63(5):600-13.

Hirata H, Yoshiura S, Ohtsuka T, Bessho Y, Harada $\mathrm{T}$, Yoshikawa $\mathrm{K}$, et al. Oscillatory expression of the bHLH factor Hes1 regulated by a negative feedback loop. Science. 2002 Oct 25; 298(5594):840-3.

Hoerder-Suabedissen A, Molnár Z. Development evolution and pathology of neocortical subplate neurons. Nat Rev Neurosci. 2015 Mar; 16(3):133-46

Homem CCF, Steinmann V, Burkard TR, Jais A, Esterbauer H, Knoblich JA. Ecdysone and mediator change energy metabolism to terminate proliferation in Drosophila neural stem cells. Cell. 2014 Aug;158(4):874-88.

Huang X, Liu J, Ketova T, Fleming JT, Grover VK, Cooper MK, et al. Transventricular delivery of Sonic hedgehog is essential to cerebellar ventricular zone development. Proc Natl Acad Sci U S A. 2010 May;107(18):8422-7.

Huang Y, Song NN, Lan W, Zhang Q, Zhang L, Zhang L, et al. Sensory input is required for callosal axon targeting in the somatosensory cortex. Mol Brain. 2013;6(1):53.

Hutchins BI, Kalil K. Differential outgrowth of axons and their branches Is regulated by localized calcium transients. J Neurosci. 2008; 28(1):143-53

Hutsler JJ, Lee DG, Porter KK. Comparative analysis of cortical layering and supragranular layer enlargement in rodent carnivore and primate species. Brain Res. 2005 Aug;1052(1): 71-81.

Iacopetti P, Michelini M, Stuckmann I, Oback B, Aaku-Saraste E, Huttner WB. Expression of the antiproliferative gene TIS2 1 at the onset of neurogenesis identifies single neuroepithelial cells that switch from proliferative to neurongenerating division. Proc Natl Acad Sci U S A. 1999 Apr;96(8):4639-44.

Imayoshi I, Isomura A, Harima Y, Kawaguchi K, Kori $\mathrm{H}$, Miyachi $\mathrm{H}$, et al. Oscillatory control of factors determining multipotency and fate in mouse neural progenitors. Science. 2013 Dec;342(6163): 1203-8.

Itoh Y, Higuchi M, Oishi K, Kishi Y, Okazaki T, Sakai H, et al. PDK1-Akt pathway regulates radial neuronal migration and microtubules in the developing mouse neocortex. Proc Natl Acad Sci U S A. 2016;113(21):E2955-64.

Iwata R. Temporal differences of neurodevelopment processes between species. Neurosci Res. 2021;S0168-0102(21):00189-9.

Iwata R, Casimir P, Vanderhaeghen P. Mitochondrial dynamics in postmitotic cells regulate neurogenesis. Science. 2020;369(6505):85862.
Javaherian A, Kriegstein A. A stem cell niche for intermediate progenitor cells of the embryonic cortex. Cereb Cortex. 2009;19 Suppl 1: i70-7.

Jiang X, Nardelli J. Cellular and molecular introduction to brain development. Neurobiol Dis. 2016 Aug;92(Pt A):3-17.

Jossin Y, Cooper JA. Reelin, Rap1 and N-cadherin orient the migration of multipolar neurons in the developing neocortex. Nat Neurosci. 2011 Jun;14(6):697-703.

Kageyama R, Ohtsuka T, Shimojo H, Imayoshi I. Dynamic Notch signaling in neural progenitor cells and a revised view of lateral inhibition. Nat Neurosci. 2008 Nov;11(11):124751.

Kalebic N, Gilardi C, Albert M, Namba T, Long KR, Kostic M, et al. Human-specific ARHGAP11B induces hallmarks of neocortical expansion in developing ferret neocortex. Elife. 2018 Nov 28;7:e41241.

Kalil K, Li L, Hutchins BI. Signaling mechanisms in cortical axon growth, guidance, and branching. Front Neuroanat. 2011 Sep;5:62.

Kanton S, Boyle MJ, He Z, Santel M, Weigert A, Sanchís-Calleja F, et al. Organoid single-cell genomic atlas uncovers human-specific features of brain development. Nature. 2019 Oct 574(7778):418-22.

Katz LC, Shatz CJ. Synaptic activity and the construction of cortical circuits. Science. 1996 Nov 15;274(5290):1133-8.

Komabayashi-Suzuki M, Yamanishi E, Watanabe C, Okamura M, Tabata H, Iwai R, et al. Spatiotemporally dependent vascularization is differently utilized among neural progenitor subtypes during neocortical development. Cell Rep. 2019 Oct;29(5):1113-29.e5.

Kornack DR, Rakic P. Changes in cell-cycle kinetics during the development and evolution of primate neocortex. Proc Natl Acad Sci U S A. 1998 Feb;95(3):1242-6.

Kostović I, Judas M. The development of the subplate and thalamocortical connections in the human foetal brain. Acta Paediatr. 2010 Aug; 99(8):1119-27.

Kriegstein A, Noctor S, Martínez-Cerdeño V. Patterns of neural stem and progenitor cell division may underlie evolutionary cortical expansion. Nat Rev Neurosci. 2006 Nov;7(11): 883-90.

Lamus F, Martín C, Carnicero E, Moro JA, Fernández JMF, Mano A, et al. FGF2/EGF contributes to brain neuroepithelial precursor proliferation and neurogenesis in rat embryos: the involvement of embryonic cerebrospinal fluid. Dev Dyn. 2020 Jan;249(1):141-53.

Lancaster MA, Renner M, Martin CA, Wenzel D, Bicknell LS, Hurles ME, et al. Cerebral organoids model human brain development and microcephaly. Nature. 2013 Sep;501(7467): 373-79.

Lange C, Huttner WB, Calegari F. Cdk4/cyclin D1 overexpression in neural stem cells shortens G1, delays neurogenesis, and promotes the generation and expansion of basal progenitors. Cell Stem Cell. 2009 Sep;5(3):320-31. 
Lange C, Turrero Garcia M, Decimo I, Bifari F, Eelen G, Quaegebeur A, et al. Relief of hypoxia by angiogenesis promotes neural stem cell differentiation by targeting glycolysis. EMBO J. 2016;35(9):924-41.

Lehtinen MK, Walsh CA. Neurogenesis at the brain-cerebrospinal fluid interface. Annu Rev Cell Dev Biol. 2011;27:653-79.

Lehtinen MK, Zappaterra MW, Chen X, Yang YJ, Hill AD, Lun M, et al. The cerebrospinal fluid provides a proliferative niche for neural progenitor cells. Neuron. 2011;69(5):893-905.

Leighton PA, Mitchell KJ, Goodrich LV, Lu X, Pinson K, Scherz P, et al. Defining brain wiring patterns and mechanisms through gene trapping in mice. Nature. 2001 Mar; 410(6825):174-9.

Leonard LB. Children with specific language impairment. Cambridge: MIT Press; 1998.

Lewitus E, Kelava I, Kalinka AT, Tomancak P, Huttner WB. An adaptive threshold in mammalian neocortical evolution. PLoS Biol. 2014;12(11):e1002000.

Li ML, Tang H, Shao Y, Wang MS, Xu HB, Wang $\mathrm{S}$, et al. Evolution and transition of expression trajectory during human brain development. BMC Evol Biol. 2020 Jun;20(1):72.

Li Y, Van Hooser SD, Mazurek M, White LE, Fitzpatrick D. Experience with moving visual stimuli drives the early development of cortical direction selectivity. Nature. 2008 Dec; 456(7224):952-6.

Lickiss T, Cheung AFP, Hutchinson CE, Taylor JSH, Molnár Z. Examining the relationship between early axon growth and transcription factor expression in the developing cerebral cortex. J Anat. 2012 Jan;220(3):201.

Linaro D, Vermaercke B, Iwata R, Ramaswamy A, Libé-Philippot B, Boubakar L, et al. Xenotransplanted human cortical neurons reveal species-specific development and functional integration into mouse visual circuits. Neuron. 2019 Dec;104(5):972-86.e6.

Liu X, Somel M, Tang L, Yan Z, Jiang X, Guo S, et al. Extension of cortical synaptic development distinguishes humans from chimpanzees and macaques. Genome Res. 2012 Apr;22(4):61122.

Llorca A, Ciceri G, Beattie R, Wong FK, Diana G, Serafeimidou-Pouliou E, et al. A stochastic framework of neurogenesis underlies the assembly of neocortical cytoarchitecture. eLife. 2019 Nov;8:e51381.

López-Bendito G, Chan CH, Mallamaci A, Parnavelas J, Molnár Z. Role of Emx2 in the development of the reciprocal connectivity between cortex and thalamus. J Comp Neurol. 2002 Sep;451(2):153-69.

LoTurco JJ, Owens DF, Heath MJ, Davis MB, Kriegstein AR. GABA and glutamate depolarize cortical progenitor cells and inhibit DNA synthesis. Neuron. 1995 Dec;15(6):1287-98.

Lukaszewicz A, Savatier P, Cortay V, Giroud P, Huissoud C, Berland M, et al. G1 phase regulation, area-specific cell cycle control, and cytoarchitectonics in the primate cortex. Neuron. 2005;47(3):353-64.
Lukaszewicz A, Savatier P, Cortay V, Kennedy H, Dehay C. Contrasting effects of basic fibroblast growth factor and neurotrophin 3 on cell cycle kinetics of mouse cortical stem cells. J Neurosci. 2002 Aug;22(15):6610-22.

Magrinelli E, Wagener RJ, Jabaudon D. Simultaneous production of diverse neuronal subtypes during early corticogenesis. bioRxiv. 2018;2018:369678.

Mairet-Coello G, Tury A, DiCicco-Bloom E. Insulin-like growth factor-1 promotes $\mathrm{G}(1) / \mathrm{S}$ cell cycle progression through bidirectional regulation of cyclins and cyclin-dependent kinase inhibitors via the phosphatidylinositol 3-kinase/Akt pathway in developing rat cerebral cortex. J Neurosci. 2009;29(3):775-88.

Malmersjö S, Rebellato P, Smedler E, Planert H, Kanatani S, Liste I, et al. Neural progenitors organize in small-world networks to promote cell proliferation. Proc Natl Acad Sci U S A. 2013;110(16):E1524-32.

Marchetto MC, Hrvoj-Mihic B, Kerman BE, Yu DX, Vadodaria KC, Linker SB, et al. Speciesspecific maturation profiles of human, chimpanzee and bonobo neural cells. eLife. 2019 Feb;8:e37527.

Marín O. Developmental timing and critical windows for the treatment of psychiatric disorders. Nat Med. 2016 Nov;22(11):1229-38.

Martinez-Garay I, Gil-Sanz C, Franco SJ, Espinosa A, Molnár Z, Mueller U. Cadherin 2/4 signaling via PTP1B and catenins is crucial for nucleokinesis during radial neuronal migration in the neocortex. Development. 2016 Jun; 143(12):2121-34

Mire E, Hocine M, Bazellières E, Jungas T, Davy A, Chauvet S, et al. Developmental upregulation of Ephrin-B1 silences Sema3C/Neuropilin-1 signaling during post-crossing navigation of corpus callosum axons. Curr Biol. 2018 Jun;28(11):1768-82.e4.

Mire E, Mezzera C, Leyva-Diaz E, Paternain AV, Squarzoni P, Bluy L, et al. Spontaneous activity regulates Robol transcription to mediate a switch in thalamocortical axon growth. Nat Neurosci. 2012;15(8):1134-43.

Mitchell-Dick A, Chalem A, Pilaz LJ, Silver DL. Acute lengthening of progenitor mitosis influences progeny fate during cortical development in vivo. Dev Neurosci. 2019;41(5-6): 300-17.

Miyoshi G, Fishell G. Dynamic FoxG1 expression coordinates the integration of multipolar pyramidal neuron precursors into the cortical plate. Neuron. 2012 Jun;74(6):1045-58.

Mizuno H, Hirano T, Tagawa Y. Evidence for activity-dependent cortical wiring: formation of interhemispheric connections in neonatal mouse visual cortex requires projection neuron activity. J Neurosci. 2007 Jun;27(25): 6760-70.

Mizuno H, Hirano T, Tagawa Y. Pre-synaptic and post-synaptic neuronal activity supports the axon development of callosal projection neurons during different post-natal periods in the mouse cerebral cortex. Eur J Neurosci. 2010; 31(3):410-24.
Molina A, Bonnet F, Lobjois V, Bel-Vialar S, Gautrais J, Pituello F, et al. G1 phase lengthening during neural tissue development involves CDC25B induced G1 heterogeneity. bioRxiv. 2020;2020:370833.

Molyneaux BJ, Arlotta P, Hirata T, Hibi M, Macklis JD. Fezl is required for the birth and specification of corticospinal motor neurons. Neuron. 2005;47(6):817-31.

Molyneaux BJ, Arlotta P, Menezes JR, Macklis JD. Neuronal subtype specification in the cerebral cortex. Nat Rev Neurosci. 2007;8(6):427-37.

Mora-Bermúdez F, Badsha F, Kanton S, Camp JG, Vernot B, Köhler K, et al. Differences and similarities between human and chimpanzee neural progenitors during cerebral cortex development. eLife. 2016 Sep;5:e18683.

Moreno-Juan V, Filipchuk A, Antón-Bolaños N, Mezzera C, Gezelius H, Andrés B, et al. Prenatal thalamic waves regulate cortical area size prior to sensory processing. Nat Commun. 2017 Feb;8(1):14172.

Mouveroux JM, Verkijk M, Lakke EA, Marani E. Intrinsic properties of the developing motor cortex in the rat: in vitro axons from the medial somatomotor cortex grow faster than axons from the lateral somatomotor cortex. Brain Res Dev Brain Res. 2000 Jul;122(1):5966.

Nadarajah B, Brunstrom JE, Grutzendler J, Wong RO, Pearlman AL. Two modes of radial migration in early development of the cerebral cortex. Nat Neurosci. 2001 Feb;4(2):143-50.

Najas S, Pijuan I, Esteve-Codina A, Usieto S, Martinez JD, Zwijsen A, et al. A SMAD1/5-YAP signalling module drives radial glia self-amplification and growth of the developing cerebral cortex. Development. 2020;147(13): $\operatorname{dev} 187005$.

Nelson BR, Hodge RD, Bedogni F, Hevner RF. Dynamic interactions between intermediate neurogenic progenitors and radial glia in embryonic mouse neocortex: potential role in Dll1-Notch signaling. I Neurosci. 2013; 33(21):9122-39.

Nichols AJ, Carney LH, Olson EC. Comparison of slow and fast neocortical neuron migration using a new in vitro model. BMC Neurosci. 2008;9:50.

Nieto M, Schuurmans C, Britz O, Guillemot F. Neural bHLH genes control the neuronal versus glial fate decision in cortical progenitors. Neuron. 2001 Feb;29(2):401-13.

Noctor SC, Flint AC, Weissman TA, Dammerman RS, Kriegstein AR. Neurons derived from radial glial cells establish radial units in neocortex. Nature. 2001 Feb;409(6821):71420.

Noctor SC, Martínez-Cerdeño V, Ivic L, Kriegstein AR. Cortical neurons arise in symmetric and asymmetric division zones and migrate through specific phases. Nat Neurosci. 2004 Feb;7(2):136-44.

Oberst P, Fièvre S, Baumann N, Concetti C, Bartolini G, Jabaudon D. Temporal plasticity of apical progenitors in the developing mouse neocortex. Nature. 2019 Sep;573(7774):370-4. 
Ochi S, Imaizumi Y, Shimojo H, Miyachi H, Kageyama R. Oscillatory expression of Hes 1 regulates cell proliferation and neuronal differentiation in the embryonic brain. Development. 2020;147(4):dev182204.

Ogawa M, Miyata T, Nakajima K, Yagyu K, Seike $\mathrm{M}$, Ikenaka K, et al. The reeler gene-associated antigen on Cajal-Retzius neurons is a crucial molecule for laminar organization of cortical neurons. Neuron. 1995 May;14(5):899-912.

Ohara Y, Koganezawa N, Yamazaki H, Roppongi RT, Sato K, Sekino Y, et al. Early-stage development of human induced pluripotent stem cell-derived neurons. J Neurosci Res. 2015; 93(12):1804-13.

Ohno S. Evolution by gene duplication. Berlin: Springer Science \& Business Media; 1970.

Ohtaka-Maruyama C, Okamoto M, Endo K, Oshima M, Kaneko N, Yura K, et al. Synaptic transmission from subplate neurons controls radial migration of neocortical neurons. Science. 2018;360(6386):313-17.

Okamoto M, Miyata T, Konno D, Ueda HR, Kasukawa T, Hashimoto M, et al. Cell-cycle-independent transitions in temporal identity of mammalian neural progenitor cells. Nat Commun. 2016 Apr;7(1):11349.

Olson EC. Analysis of preplate splitting and early cortical development illuminates the biology of neurological disease. Front Pediatr. 2014;2: $121-21$.

Otani T, Marchetto MC, Gage FH, Simons BD, Livesey FJ. 2D and 3D stem cell models of primate cortical development identify speciesspecific differences in progenitor behavior contributing to brain size. Cell Stem Cell. 2016 Apr;18(4):467-80.

Owens DF, Kriegstein AR. Patterns of intracellular calcium fluctuation in precursor cells of the neocortical ventricular zone. J Neurosci. 1998;18(14):5374-88.

Oyama S. A sensitive period for the acquisition of a nonnative phonological system. J Psycholinguist Res. 1976 Jul;5(3):261-83.

Ozair MZ, Kirst C, van den Berg BL, Ruzo A, Rito $\mathrm{T}$, Brivanlou AH. HPSC modeling reveals that fate selection of cortical deep projection neurons occurs in the subplate. Cell Stem Cell. 2018 Jul 5;23(1):60-e6.

Paolino A, Fenlon LR, Kozulin P, Haines E, Lim JWC, Richards LJ, et al. Differential timing of a conserved transcriptional network underlies divergent cortical projection routes across mammalian brain evolution. Proc Natl Acad Sci U S A. 2020;117(19):10554-64.

Paolino A, Fenlon LR, Suárez R, Richards LJ. Transcriptional control of long-range cortical projections. Curr Opin Neurobiol. 2018 Dec; 53:57-65.

Parthasarathy S, Srivatsa S, Nityanandam A, Tarabykin V. Ntf3 acts downstream of Sip1 in cortical postmitotic neurons to control progenitor cell fate through feedback signaling. Development. 2014;141(17):3324-30.
Pearson CA, Moore DM, Tucker HO, Dekker JD, $\mathrm{Hu} \mathrm{H}$, Miquelajáuregui A, et al. Foxp1 regulates neural stem cell self-renewal and bias toward deep layer cortical fates. Cell Rep. 2020 Feb;30(6):1964-81.e3.

Petanjek Z, Judaš M, Šimić G, Rašin MR, Uylings HBM, Rakic P, et al. Extraordinary neoteny of synaptic spines in the human prefrontal cortex. Proc Natl Acad Sci U S A. 2011;108(32): 13281-86.

Picco N, García-Moreno F, Maini PK, Woolley TE, Molnár Z. Mathematical modeling of cortical neurogenesis reveals that the founder population does not necessarily scale with neurogenic output. Cereb Cortex. 2018;28(7): 2540-50.

Pilaz LJ, McMahon JJ, Miller EE, Lennox AL, Suzuki A, Salmon E, et al. Prolonged mitosis of neural progenitors alters cell fate in the developing brain. Neuron. 2016 Jan;89(1):83-99.

Pilaz LJ, Patti D, Marcy G, Ollier E, Pfister S, Douglas RJ, et al. Forced G1-phase reduction alters mode of division, neuron number, and laminar phenotype in the cerebral cortex. Proc Natl Acad Sci U S A. 2009;106(51): 21924-29.

Pinson A, Huttner WB. Neocortex expansion in development and evolution - from genes to progenitor cell biology. Curr Opin Cell Biol. 2021;73:9-18.

Pollen AA, Bhaduri A, Andrews MG, Nowakowski TJ, Meyerson OS, Mostajo-Radji MA, et al. Establishing cerebral organoids as models of human-specific brain evolution. Cell. 2019 Feb;176(4):743-56.e17.

Polleux F, Dehay C, Kennedy H. The timetable of laminar neurogenesis contributes to the specification of cortical areas in mouse isocortex. J Comp Neurol. 1997;385(1):95-116.

Pouchelon G, Gambino F, Bellone C, Telley L, Vitali I, Luscher C, et al. Modality-specific thalamocortical inputs instruct the identity of postsynaptic L4 neurons. Nature. 2014; 511(7510):471-4.

Qian X, Shen Q, Goderie SK, He W, Capela A, Davis AA, et al. Timing of CNS cell generation: a programmed sequence of neuron and glial cell production from isolated murine cortical stem cells. Neuron. 2000 Oct;28(1): 69-80.

Rakic P. A small step for the cell, a giant leap for mankind: a hypothesis of neocortical expansion during evolution. Trends Neurosci. 1995 Sep;18(9):383-8.

Rash BG, Ackman JB, Rakic P. Bidirectional radial Ca2+ activity regulates neurogenesis and migration during early cortical column formation. Sci Adv. 2016;2(2):e1501733.

Rashid M, Belmont J, Carpenter D, Turner CE, Olson EC. Neural-specific deletion of the focal adhesion adaptor protein paxillin slows migration speed and delays cortical layer formation. Development. 2017;144(21):400214.
Reillo I, de Juan Romero C, Cárdenas A, Clascá F, Martínez-Martinez MÁ, Borrell V. A complex code of extrinsic influences on cortical progenitor cells of higher mammals. Cereb Cortex. 2017;27(9):4586-606.

Reillo I, de Juan Romero C, García-Cabezas MÁ, Borrell V. A role for intermediate radial glia in the tangential expansion of the mammalian cerebral cortex. Cereb Cortex. 2010;21(7): 1674-94.

Rice FL, Van Der Loos H. Development of the barrels and barrel field in the somatosensory cortex of the mouse. J Comp Neurol. 1977; 171(4):545-60.

Richards LJ, Koester SE, Tuttle R, O'Leary DD. Directed growth of early cortical axons is influenced by a chemoattractant released from an intermediate target. J Neurosci. 1997; 17(7):2445-58

Rodriguez M, Choi J, Park S, Sockanathan S. Gde2 regulates cortical neuronal identity by controlling the timing of cortical progenitor differentiation. Development. 2012 Oct;139(20): 3870-9.

Sahara S, O'Leary DD. Fgf10 regulates transition period of cortical stem cell differentiation to radial glia controlling generation of neurons and basal progenitors. Neuron. $2009 \mathrm{Jul}$; 63(1):48-62.

Sanosaka T, Imamura T, Hamazaki N, Chai M, Igarashi $\mathrm{K}$, Ideta-Otsuka $\mathrm{M}$, et al. DNA methylome analysis identifies transcription factorbased epigenomic signatures of multilineage competence in neural stem/progenitor cells. Cell Rep. 2017 Sep;20(12):2992-3003.

Sardi SP, Murtie J, Koirala S, Patten BA, Corfas G Presenilin-dependent ErbB4 nuclear signaling regulates the timing of astrogenesis in the developing brain. Cell. 2006 Oct;127(1):18597.

Schörnig M, Ju X, Fast L, Ebert S, Weigert A, Kanton $\mathrm{S}$, et al. Comparison of induced neurons reveals slower structural and functional maturation in humans than in apes. eLife. 2021 Jan;10:e59323.

Seuntjens E, Nityanandam A, Miquelajauregui A, Debruyn J, Stryjewska A, Goebbels S, et al. Sip1 regulates sequential fate decisions by feedback signaling from postmitotic neurons to progenitors. Nat Neurosci. 2009 Nov; 12(11):1373-80.

Shen Q, Wang Y, Dimos JT, Fasano CA, Phoenix TN, Lemischka IR, et al. The timing of cortical neurogenesis is encoded within lineages of individual progenitor cells. Nat Neurosci. 2006 Jun;9(6):743-51.

Shimojo H, Ohtsuka T, Kageyama R. Oscillations in notch signaling regulate maintenance of neural progenitors. Neuron. 2008 Apr;58(1): 52-64.

Shinmyo Y, Kawasaki H. CRISPR/Cas9-mediated gene knockout in the mouse brain using in utero electroporation. Curr Protoc Neurosci. 2017 Apr;79:332.1-11. 
Shu P, Wu C, Ruan X, Liu W, Hou L, Fu H, et al. Opposing gradients of microRNA expression temporally pattern layer formation in the developing neocortex. Dev Cell. 2019 Jun;49(5): 764-85.e4.

Siegenthaler JA, Ashique AM, Zarbalis K, Patterson KP, Hecht JH, Kane MA, et al. Retinoic acid from the meninges regulates cortical neuron generation. Cell. 2009 Oct;139(3): 597-609.

Silva CG, Peyre E, Adhikari MH, Tielens S, Tanco S, Van Damme P, et al. Cell-intrinsic control of interneuron migration drives cortical morphogenesis. Cell. 2018;172(5):1063-78.e19.

Silva CG, Peyre E, Nguyen L. Cell migration promotes dynamic cellular interactions to control cerebral cortex morphogenesis. Nat Rev Neurosci. 2019 Jun;20(6):318-29.

Siqueira M, Francis D, Gisbert D, Gomes FCA, Stipursky J. Radial glia cells control angiogenesis in the developing cerebral cortex through TGF- $\beta 1$ signaling. Mol Neurobiol. 2018 May; 55(5):3660-75.

Somel M, Franz H, Yan Z, Lorenc A, Guo S, Giger $\mathrm{T}$, et al. Transcriptional neoteny in the human brain. Proc Natl Acad Sci U S A. 2009;106(14): 5743-8.

Somel M, Liu X, Tang L, Yan Z, Hu H, Guo S, et al. microRNA-driven developmental remodeling in the brain distinguishes humans from other primates. PLoS Biol. 2011;9(12): e1001214.

Srinivasan K, Leone DP, Bateson RK, Dobreva G, Kohwi Y, Kohwi-Shigematsu T, et al. A network of genetic repression and derepression specifies projection fates in the developing neocortex. Proc Natl Acad Sci U S A. 2012 Nov;109(47):19071-78.

Stepien BK, Naumann R, Holtz A, Helppi J, Huttner WB, Vaid S. Lengthening neurogenic period during neocortical development causes a hallmark of neocortex expansion. Curr Biol. 2020 Nov;30(21):4227-37.e5.

Stepien BK, Vaid S, Huttner WB. Length of the neurogenic period: a key determinant for the generation of upper-layer neurons during neocortex development and evolution. Front Cell Dev Biol. 2021 May;9:676911.

Stoeckli ET. Understanding axon guidance: are we nearly there yet?. Development. 2018; 145(10):dev151415.

Suárez R, Fenlon LR, Marek R, Avitan L, Sah P, Goodhill GJ, et al. Balanced interhemispheric cortical activity is required for correct targeting of the corpus callosum. Neuron. 2014; 82(6):1289-98.

Suárez R, Paolino A, Fenlon LR, Morcom LR, Kozulin P, Kurniawan ND, et al. A pan-mammalian map of interhemispheric brain connections predates the evolution of the corpus callosum. Proc Natl Acad Sci U S A. 2018; 115(38):9622-27.

Supèr H, Del Río JA, Martínez A, Pérez-Sust P, Soriano E. Disruption of neuronal migration and radial glia in the developing cerebral cortex following ablation of Cajal-Retzius cells. Cereb Cortex. 2000 Jun;10(6):602-13.
Suzuki IK. Molecular drivers of human cerebral cortical evolution. Neurosci Res. 2020 Feb; 151:1-14.

Suzuki IK, Gacquer D, Van Heurck R, Kumar D, Wojno M, Bilheu A, et al. Human-specific NOTCH2NL genes expand cortical neurogenesis through Delta/Notch regulation. Cell. 2018 May;173(6):1370-84.e16.

Tabata H, Nakajima K. Multipolar migration: the third mode of radial neuronal migration in the developing cerebral cortex. J Neurosci. 2003;23(31):9996-10001.

Takahashi T, Goto T, Miyama S, Nowakowski RS, Caviness VS Jr. Sequence of neuron origin and neocortical laminar fate: relation to cell cycle of origin in the developing murine cerebral wall. J Neurosci. 1999;19(23):10357-71.

Takahashi T, Nowakowski RS, Caviness VS Jr. The cell cycle of the pseudostratified ventricular epithelium of the embryonic murine cerebral wall. J Neurosci. 1995 Sep;15(9):6046-57.

Takebayashi K, Sasai Y, Sakai Y, Watanabe T, Nakanishi S, Kageyama R. Structure, chromosomal locus, and promoter analysis of the gene encoding the mouse helix-loop-helix factor HES-1. Negative autoregulation through the multiple $\mathrm{N}$ box elements. J Biol Chem. 1994 Feb;269(7):5150-6.

Telley L, Agirman G, Prados J, Amberg N, Fièvre $S$, Oberst $\mathrm{P}$, et al. Temporal patterning of apical progenitors and their daughter neurons in the developing neocortex. Science. 2019; 364(6440):eaav2522.

Toma K, Kumamoto T, Hanashima C. The timing of upper-layer neurogenesis is conferred by sequential derepression and negative feedback from deep-layer neurons. J Neurosci. 2014;34(39):13259-76.

Tyzio R, Nardou R, Ferrari DC, Tsintsadze T, Shahrokhi A, Eftekhari S, et al. Oxytocin-mediated GABA inhibition during delivery attenuates autism pathogenesis in rodent offspring. Science. 2014 Feb;343(6171):675-9.

Uesaka N, Hirai S, Maruyama T, Ruthazer ES, Yamamoto N. Activity dependence of cortical axon branch formation: a morphological and electrophysiological study using organotypic slice cultures. J Neurosci. 2005 Jan;25(1):1-9.

Vaccarino FM, Schwartz ML, Raballo R, Nilsen J, Rhee J, Zhou M, et al. Changes in cerebral cortex size are governed by fibroblast growth factor during embryogenesis. Nat Neurosci. 1999 Mar;2(3):246-53.

Vaid S, Camp JG, Hersemann L, Eugster Oegema C, Heninger A-K, Winkler S, et al. A novel population of Hopx-dependent basal radial glial cells in the developing mouse neocortex. Development. 2018;145(20):dev169276.

Van der Loos H, Woolsey TA. Somatosensory cortex: structural alterations following early injury to sense organs. Science. 1973 Jan; 179(4071):395-98.
Van Hooser SD, Li Y, Christensson M, Smith GB, White LE, Fitzpatrick D. Initial neighborhood biases and the quality of motion stimulation jointly influence the rapid emergence of direction preference in visual cortex. J Neurosci. 2012 May;32(21):7258-66.

Vitali I, Fièvre S, Telley L, Oberst P, Bariselli S, Frangeul L, et al. Progenitor hyperpolarization regulates the sequential generation of neuronal subtypes in the developing neocortex. Cell. 2018 Aug;174(5):1264-76.e15.

Wagenführ L, Meyer AK, Braunschweig L, Marrone $\mathrm{L}$, Storch A. Brain oxygen tension controls the expansion of outer subventricular zone-like basal progenitors in the developing mouse brain. Development. 2015;142(17): 2904-15.

Wang CL, Zhang L, Zhou Y, Zhou J, Yang XJ, Duan SM, et al. Activity-dependent development of callosal projections in the somatosensory cortex. J Neurosci. 2007 Oct;27(42): 11334-42.

Wang W, Jossin Y, Chai G, Lien WH, Tissir F, Goffinet AM. Feedback regulation of apical progenitor fate by immature neurons through Wnt7-Celsr3-Fzd3 signalling. Nat Commun. 2016 Mar;7(1):10936.

Weber-Fox C, Neville HJ. Maturational constraints on functional specializations for language processing: ERP and behavioral evidence in bilingual speakers. J Cogn Neurosci. 1996;8(3):231-56.

Weissman TA, Riquelme PA, Ivic L, Flint AC, Kriegstein AR. Calcium waves propagate through radial glial cells and modulate proliferation in the developing neocortex. Neuron. 2004 Sep;43(5):647-61.

Wiesel TN, Hubel DH. Extent of recovery from the effects of visual deprivation in kittens. J Neurophysiol. 1965 Nov;28(6):1060-72.

Wildman DE, Uddin M, Liu G, Grossman LI, Goodman M. Implications of natural selection in shaping $99.4 \%$ nonsynonymous DNA identity between humans and chimpanzees: enlarging genus Homo. Proc Natl Acad Sci U S A. 2003;100(12):7181-88.

Wilson NH, Stoeckli ET. Sonic hedgehog regulates its own receptor on postcrossing commissural axons in a glypican1-dependent manner. Neuron. 2013 Aug;79(3):478-91.

Wong FK, Bercsenyi K, Sreenivasan V, Portalés A, Fernández-Otero M, Marín O. Pyramidal cell regulation of interneuron survival sculpts cortical networks. Nature. 2018;557(7707): 668-73.

Workman AD, Charvet CJ, Clancy B, Darlington RB, Finlay BL. Modeling transformations of neurodevelopmental sequences across mammalian species. J Neurosci. 2013;33(17): 7368-83.

Wu QF, Yang L, Li S, Wang Q, Yuan XB, Gao X, et al. Fibroblast growth factor 13 is a microtubule-stabilizing protein regulating neuronal polarization and migration. Cell. 2012 Jun; 149(7):1549-64. 
Xie S, Skotheim JM. A G1 sizer coordinates growth and division in the mouse epidermis. Curr Biol. 2020 Mar;30(5):916-24.e2.

Xing L, Kubik-Zahorodna A, Namba T, Pinson A, Florio M, Prochazka J, et al. Expression of human-specific ARHGAP11B in mice leads to neocortex expansion and increased memory flexibility. EMBO J. 2021;40(13):e107093.

Yam PT, Kent CB, Morin S, Farmer WT, Alchini $\mathrm{R}$, Lepelletier $\mathrm{L}$, et al. 14-3-3 proteins regulate a cell-intrinsic switch from Sonic hedgehogmediated commissural axon attraction to repulsion after midline crossing. Neuron. 2012 Nov;76(4):735-49.
Yang EJ, Lin EW, Hensch TK. Critical period for acoustic preference in mice. Proc Natl Acad Sci U S A. 2012;109 Suppl 2:17213-20.

Yang L, Garbe DS, Bashaw GJ. A Frazzled/DCCdependent transcriptional switch regulates midline axon guidance. Science. 2009; 324(5929):944-47.

Yoon KJ, Koo BK, Im SK, Jeong HW, Ghim J, Kwon MC, et al. Mind bomb 1-expressing intermediate progenitors generate notch signaling to maintain radial glial cells. Neuron. 2008 May;58(4):519-31.
Yoon KJ, Ringeling FR, Vissers C, Jacob F, Pokrass $\mathrm{M}$, Jimenez-Cyrus $\mathrm{D}$, et al. Temporal control of mammalian cortical neurogenesis by $\mathrm{m} 6 \mathrm{~A}$ methylation. Cell. 2017 Nov;171(4):877-89. e17.

Zahr SK, Yang G, Kazan H, Borrett MJ, Yuzwa SA, Voronova A, et al. A translational repression complex in developing mammalian neural stem cells that regulates neuronal specification. Neuron. 2018 Feb;97(3):520-37.e6.

Zappaterra MW, Lehtinen MK. The cerebrospinal fluid: regulator of neurogenesis, behavior, and beyond. Cell Mol Life Sci. 2012 Sep; 69(17):2863-78. 